\title{
Exploring Earth's atmosphere with radio occultation: contributions to weather, climate and space weather
}

\author{
R. A. Anthes \\ University Corporation for Atmospheric Research, 3090 Center Green Drive, Boulder, Colorado 80301, USA \\ Received: 12 November 2010 - Published in Atmos. Meas. Tech. Discuss.: 11 January 2011 \\ Revised: 3 May 2011 - Accepted: 16 May 2011 - Published: 16 June 2011
}

\begin{abstract}
The launch of the proof-of-concept mission GPS/MET (Global Positioning System/Meteorology) in 1995 began a revolution in profiling Earth's atmosphere through radio occultation (RO). GPS/MET; subsequent single-satellite missions CHAMP (CHAllenging Minisatellite Payload), SAC-C (Satellite de Aplicaciones CientificasC), GRACE (Gravity Recovery and Climate Experiment), METOP-A, and TerraSAR-X (Beyerle et al., 2010); and the six-satellite constellation, FORMOSAT-3/COSMIC (Formosa Satellite mission \#3/Constellation Observing System for Meteorology, Ionosphere, and Climate) have proven the theoretical capabilities of RO to provide accurate and precise profiles of electron density in the ionosphere and refractivity, containing information on temperature and water vapor, in the stratosphere and troposphere. This paper summarizes results from these RO missions and the applications of RO observations to atmospheric research and operational weather analysis and prediction.
\end{abstract}

\section{Introduction}

The Global Positioning System (GPS) radio occultation (RO) limb sounding technique for sounding Earth's atmosphere was demonstrated by the proof-of-concept GPS/Meteorology (GPS/MET) experiment in 1995-1997 (Ware et al., 1996; Kursinski et al., 1996; Rocken et al., 1997; Hocke, 1997; Steiner et al., 1999). The first RO sounding of Earth's atmosphere, which was produced by the University of Arizona, is

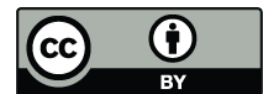

Correspondence to: R. A. Anthes (anthes@ucar.edu) shown in Fig. 1. However, the story of RO began at the dawn of interplanetary space exploration in the 1960s when a team of scientists from Stanford University and the Jet Propulsion Laboratory (JPL) used the Mariner 3 and 4 satellites to probe the atmosphere of Mars using the RO technique (Yunck et al., 2000).

In the 1980s, with the emergence of the GPS constellation, it was realized that the same RO concept that sounded the planets could be used to profile Earth's atmosphere using the GPS $\mathrm{L}_{1}(1575.42 \mathrm{MHz})$ and $\mathrm{L}_{2}(1227.60 \mathrm{MHz})$ frequencies (Gurvich and Krasil'nikova, 1987; Melbourne et al., 1994). Not until the launch of GPS/MET on 3 April 1995 was the dream realized, however, through the demonstration that RO could provide accurate high-vertical resolution soundings of Earth's atmosphere in all weather. GPS/MET demonstrated that RO could add value to the nadir sounding satellite systems (microwave and infrared) and in-situ soundings from radiosondes and aircraft.

The success of the proof-of-concept mission GPS/MET, which produced only a small number of soundings each day, led to several successful additional missions, i.e. CHAMP (CHAllenging Minisatellite Payload, Wickert et al., 2001, 2004), GRACE (Wickert et al., 2009) and SAC-C (Satellite de Aplicaciones Cientificas-C, Hajj et al., 2004). These missions confirmed the potential of RO soundings of the ionosphere, stratosphere and troposphere and paved the way for the 15 April 2006 launch of FORMOSAT-3 (Formosa Satellite mission \#3)/COSMIC (Constellation Observing System for Meteorology, Ionosphere, and Climate), hereafter referred to as COSMIC for simplicity.

COSMIC was the first constellation of satellites dedicated primarily to $\mathrm{RO}$ and delivering $\mathrm{RO}$ data in near-real-time to operational weather centers around the world (Anthes et

Published by Copernicus Publications on behalf of the European Geosciences Union. 


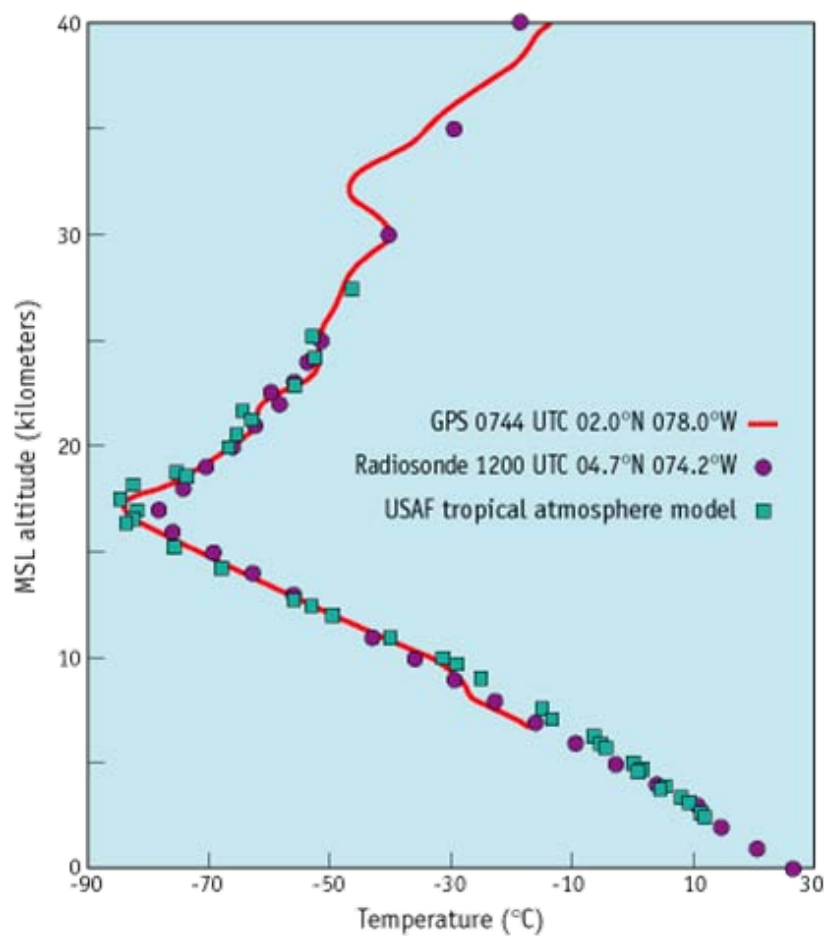

Fig. 1. The first radio occultation sounding of Earth's atmosphere. The sounding occurred at 07:44 UTC 16 April 1995 over Ecuador. The US Air Force (USAF) mean tropical atmosphere sounding and a nearby radiosonde profile are also shown. Sounding was from GPS/MET and the retrieval was done by Ben Herman at the University of Arizona. A similar version was published by Ware et al. (1996).

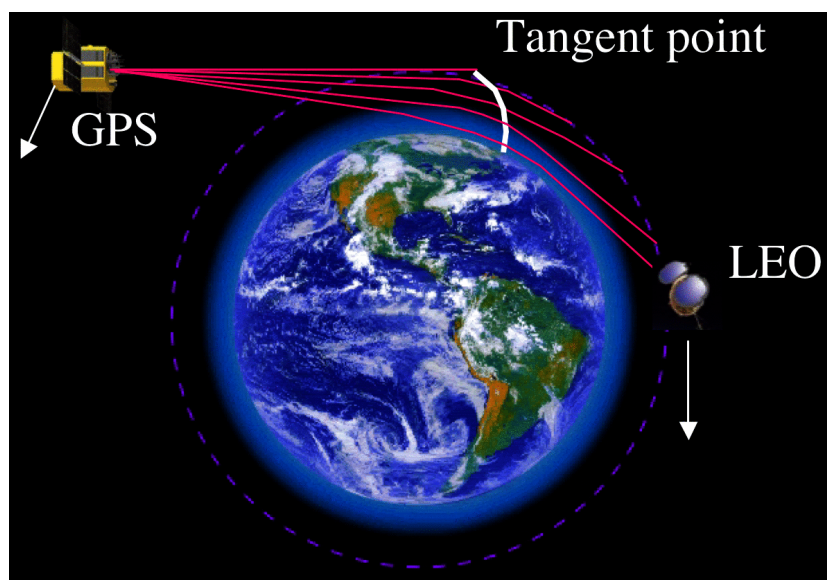

Fig. 2. Geometry of RO limb scanning technique. As the LowEarth Orbiting (LEO) satellite carrying a GPS receiver rises or sets behind Earth, a series of scans of Earth's atmosphere is obtained. The bending of the radio waves is determined through precise measurements of the phase changes and used to compute bending angle, refractivity and other products at high vertical resolution.

\section{Observed Atmospheric Volume}

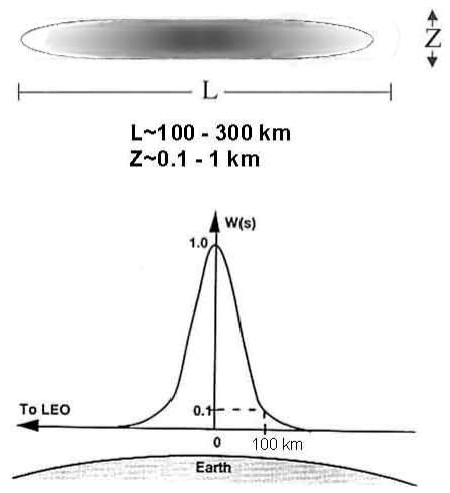

Fig. 3. Top: schematic depiction of tubular volume over which the atmosphere contributes information to a single occultation measurement. The intensity of shading in the tube represents the relative weighting of atmospheric properties that contribute to the value retrieved at the center of the tube. For typical atmospheric structures, $\mathrm{L}$ and $\mathrm{Z}$ are approximately 300 and $1 \mathrm{~km}$ respectively. Bottom: typical along-track weighting function for a single radio occultation measurement (Melbourne et al., 1994). Most of the information is contributed by a mesoscale atmospheric volume centered at the ray tangent point (Anthes et al., 2000).

al., 2008). COSMIC has produced enough global soundings each day (1500-2000) to demonstrate a significant, positive impact on operational weather forecasts, even in the presence of many more atmospheric soundings from other satellites and in-situ systems. It has justified the continuing value of $\mathrm{RO}$ as a component of the international global observing system.

This paper summarizes the results from the Earth RO missions to date that demonstrate the characteristics and value of RO observations in atmospheric phenomenological studies, operational weather prediction, climate, and space weather. Other papers that provide recent results include Anthes et al. (2008) and Hau et al. (2009).

\section{Radio occultation observations}

The RO method for obtaining atmospheric soundings is described by Kursinski et al. (1997, 2000), Lee et al. (2000), Steiner et al. (2001), Hajj et al. (2002), and Kuo et al. (2004).

\subsection{Obtaining the RO observations}

By measuring the phase delay of radio waves at $\mathrm{L}_{1}$ and $\mathrm{L}_{2}$ frequencies from GPS satellites as they are occulted by Earth's atmosphere (Fig. 2), accurate and precise vertical profiles of the bending angles of radio wave trajectories are obtained in the ionosphere, stratosphere and troposphere. From the bending angles, profiles of atmospheric refractivity 


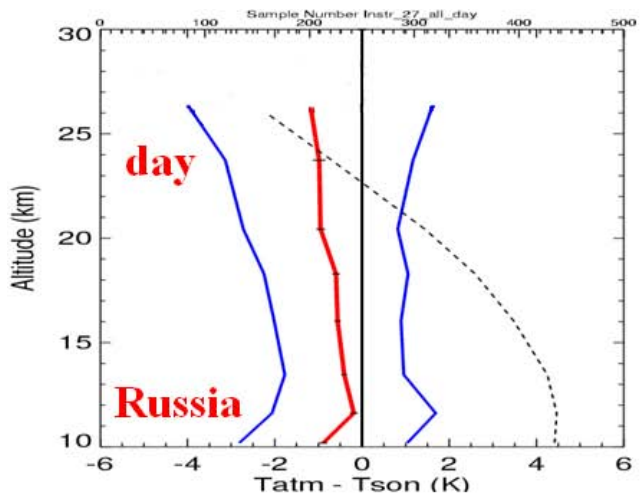

COSMIC-Radiosonde

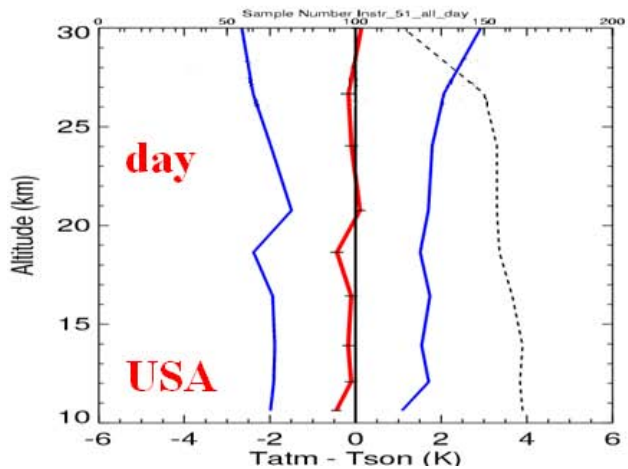

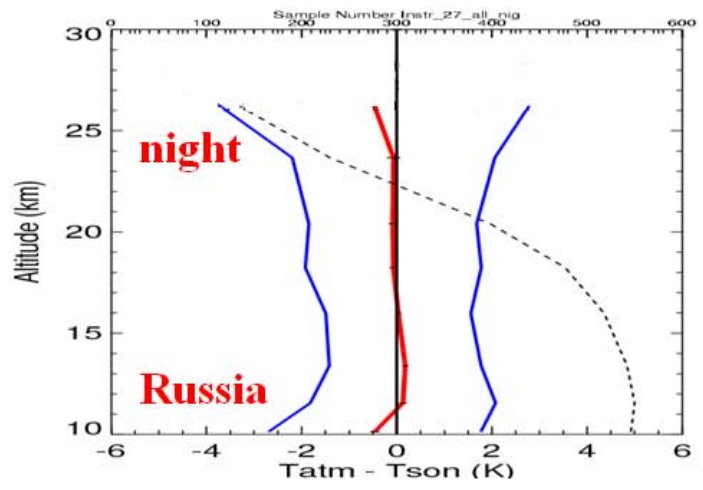

COSMIC-Radiosonde

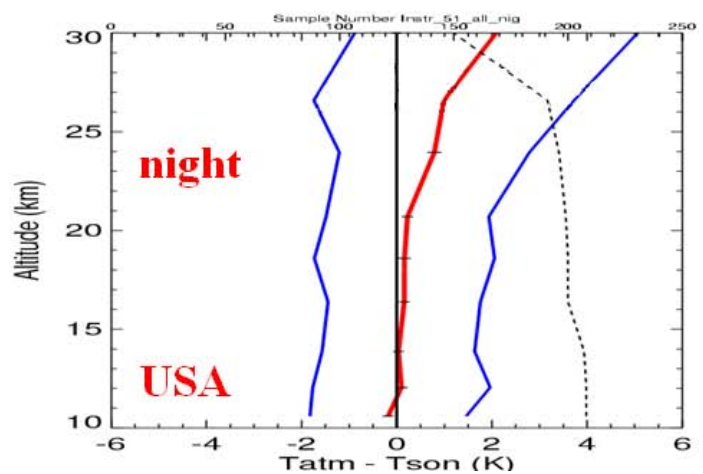

Fig. 4. Comparison of two different types of radiosonde (Russian and US) with COSMIC RO observations during the day and night. The red curves are the mean differences. The two blue curves are the standard deviation of the differences. The dashed black line is the number of pairs at each level. The RO soundings, which are not affected by sunlight, reveal biases in the Russian radiosondes during the day and the US radiosondes during the night (He et al., 2009).
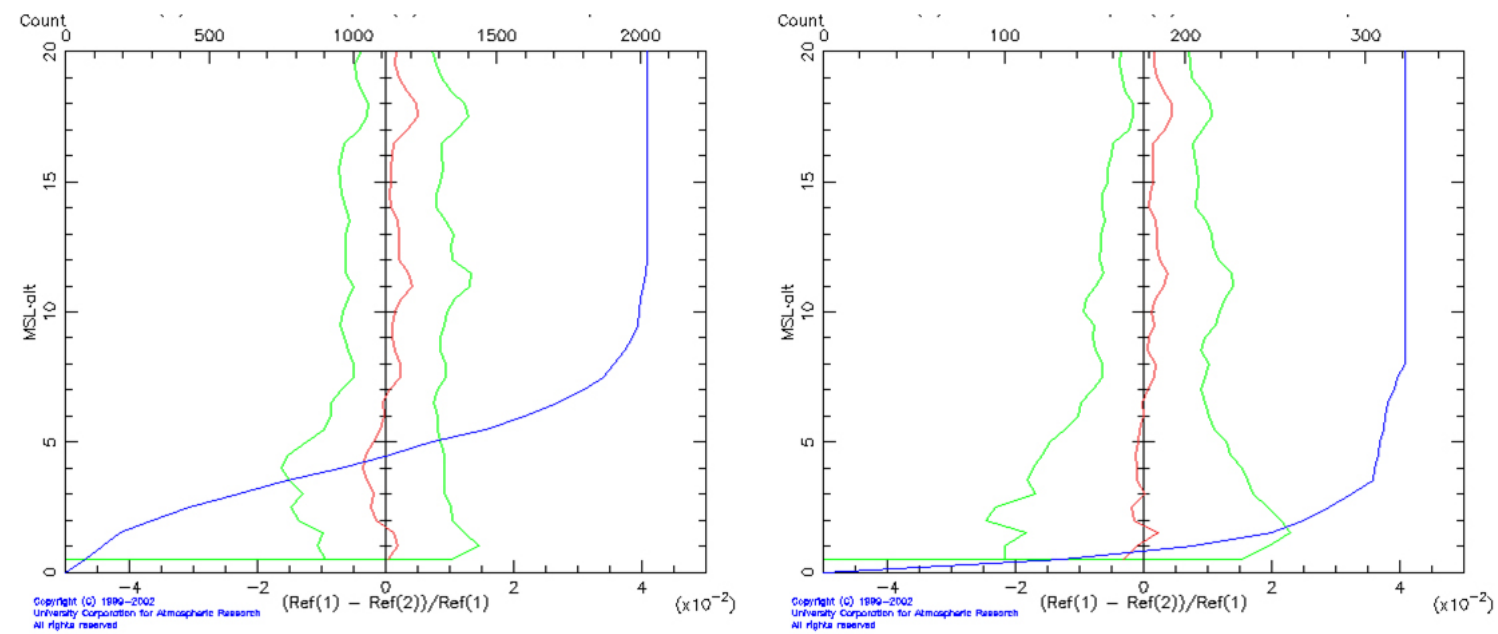

Fig. 5. Comparisons of SAC-C refractivity $(N)$ soundings obtained with phase-lock-loop (left) and open-loop (right) tracking to the ECMWF analyses interpolated to the time and place of the SAC-C soundings. The number of retrieved soundings reaching various levels in the atmosphere is shown by the blue line on the right. The mean differences are shown by the red line in the middle and the standard deviation about the mean of the differences is shown by the two green lines. The OL tracking allows for a much higher percentage of the soundings to penetrate into the lower troposphere (from UCAR COSMIC Data Analysis and Archival Center-CDAAC). 
Table 1. An early (ca. 1995) table summarizing the characteristics of RO observations.

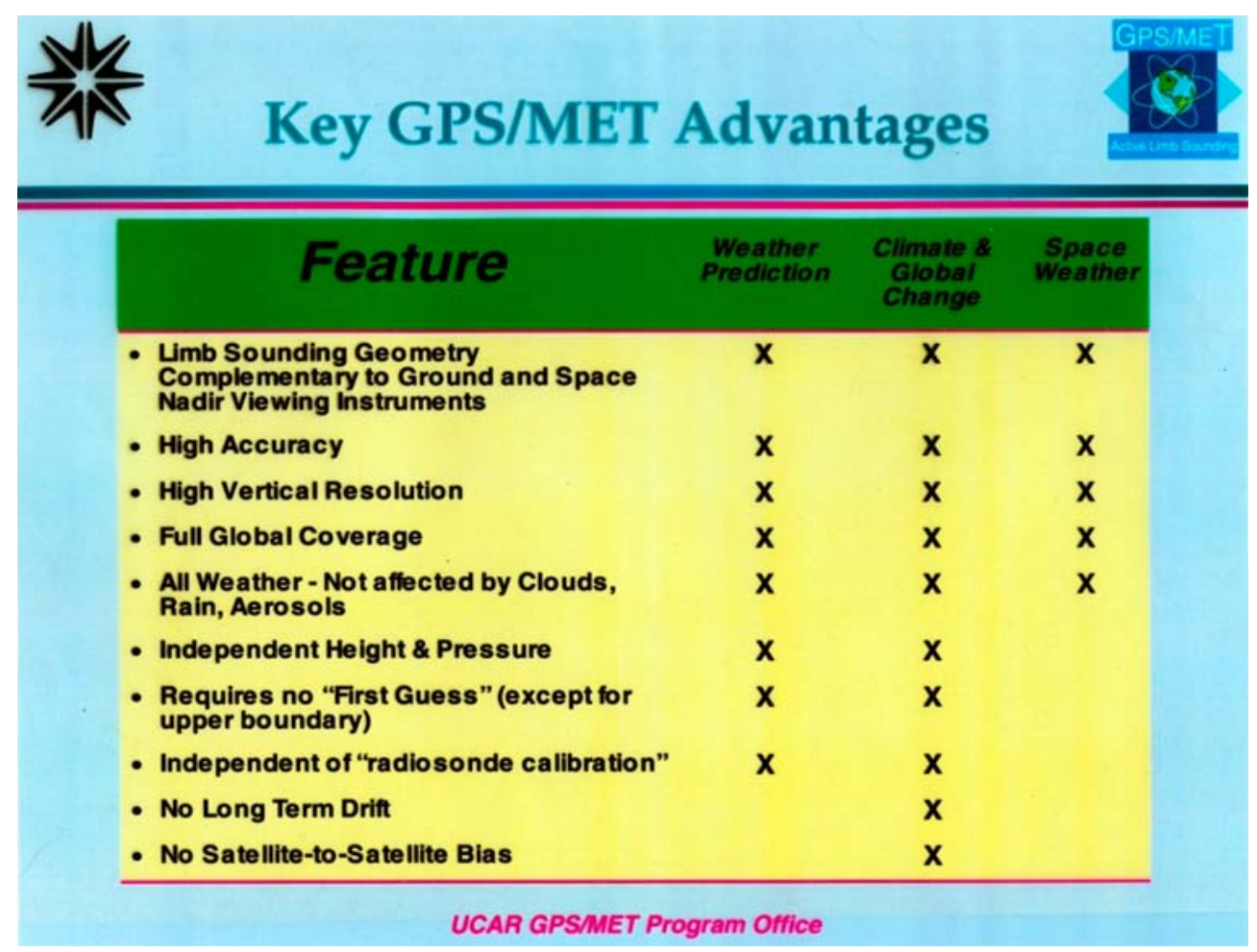

are obtained. The refractivity, $N$, is a function of temperature ( $T$ in $\mathrm{K})$, pressure ( $p$ in hPa), water vapor pressure $(e$ in $\mathrm{hPa})$, and electron density $\left(n_{\mathrm{e}}\right.$ in number of electrons per cubic meter),

$N=77.6 \frac{p}{T}+3.73 \times 10^{5} \frac{e}{T^{2}}-4.03 \times 10^{7} \frac{n_{\mathrm{e}}}{f^{2}}$

In Eq. (1), $f$ is the frequency of the GPS carrier signal in $\mathrm{Hz}$. Using $f$ equal to $\mathrm{L}_{1}$ and $\mathrm{L}_{2}$ in Eq. (1) produces two measurements, which may be linearly combined to produce an ionosphere-corrected estimate of $N$ in the stratosphere and troposphere. The refractivity profiles can be used to derive profiles of electron density in the ionosphere, temperature in the stratosphere, and temperature and water vapor in the troposphere. As seen in Eq. (1) with $n_{\mathrm{e}}=0$, in order to derive temperature (water vapor) profiles from the observed $N$, it is necessary to have independent observations of water vapor (temperature). This has been done primarily to obtain water vapor profiles in the lower troposphere given temperatures from other sources, e.g. short-term weather forecasts or even climatology. One-dimensional, variational techniques have also been used to obtain optimal estimates of temperature and water vapor from observed refractivity (e.g. Healy and Eyre, 2000). For numerical weather prediction (NWP), either refractivities or bending angles can be assimilated directly in the models, thereby contributing valuable information on both the temperature and water vapor fields simulta- neously (Healy et al., 2005; Healy and Thépaut, 2006; Chen et al., 2009).

\subsection{Characteristics of RO observations}

Before the launch of GPS/MET, theoretical considerations led to the promise of a number of unique characteristics of RO observations. Table 1 shows an early (ca. 1995) list of these characteristics, which were used to help justify the GPS/MET mission. Table 2 shows an updated version of Table 1 , based on the RO missions to date. All the promised characteristics in Table 1 have been verified (with the exception of a remaining small bias in refractivity in the lowest two $\mathrm{km}$ of the troposphere), and several of them have been quantified (e.g. accuracy and precision). In addition, new and perhaps unexpected characteristics and applications have been discovered, such as the capability of RO to provide global profiles and maps of the atmospheric boundary layer (ABL).

A unique characteristic of RO observations that has been considered a limitation for resolving mesoscale features in the atmosphere is the relatively long horizontal scale associated with a single measurement, which is of the order of $300 \mathrm{~km}$ (Fig. 3; Anthes et al., 2000). However, this property has significant advantages for some purposes, especially climate, as RO observations do not have the representativeness errors associated with small-scale atmospheric variability that point measurements (such as radiosondes) have. Yet 
Table 2. Updated characteristics of RO observations as determined by observations (Anthes et al., 2008; Ho et al., 2009a).

- Limb sounding geometry complementary to ground and space nadir viewing instruments

- Global coverage

- Profiles ionosphere, stratosphere and troposphere

- High accuracy (equivalent to $<1 \mathrm{~K}$; average accuracy $<0.1 \mathrm{~K}$

- High precision (0.02-0.05 K)

- High vertical resolution $(0.1 \mathrm{~km}$ near surface - $1 \mathrm{~km}$ tropopause)

- Only observing system from space to observe temperature and water vapor profiles in $\mathrm{ABL}$

- All weather-minimally affected by aerosols, clouds or precipitation

- Independent height and pressure

- Requires no first guess sounding

- Self calibration, no external calibration required

- Independent of processing center

- Independent of mission

- No instrument drift

- No satellite-to-satellite bias

- Compact sensor, low power, low cost

perhaps surprisingly, RO observations of temperature look very similar to the point values of temperature measured by radiosondes. In fact, as shown in Fig. 4, RO observations are capable of distinguishing the relative bias error characteristics associated with different types of radiosondes (He et al., 2009; Kuo et al., 2005).

\subsection{Improvements in RO since GPS/MET}

In spite of its overall success, there were two significant issues associated with the atmospheric profiles produced by GPS/MET. First, relatively few soundings penetrated into the lower half of the troposphere, and second, those that did showed significant refractivity errors including negative biases in the lower moist troposphere (Rocken et al., 1997; Ao et al., 2003; Beyerle et al., 2004). These errors were associated with multi-path propagation, super refraction, the relatively low gain of the GPS/MET antenna, receiver tracking errors, inversion methods using geometric optics (which are not applicable in the presence of the multipath propagation common in the lower troposphere) and the use of the so-called closed-loop (or phase-lockedloop - PLL) tracking that results in errors in the presence of multipath. These issues are discussed by Gorbunov and Gur-

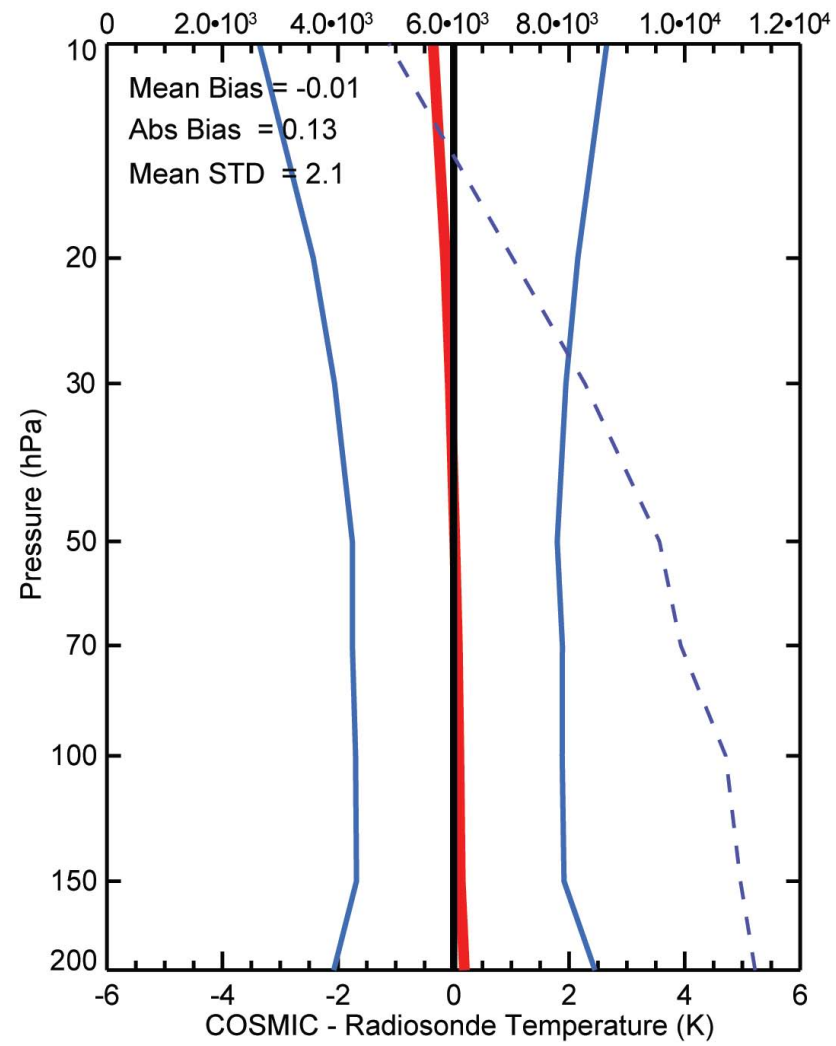

Fig. 6. Statistics of a comparison between COSMIC and highresolution, accurate radiosondes between 10 and $200 \mathrm{hPa}$. This comparison shows that the accuracy of RO observations in this region is $0.13 \mathrm{~K}$ or higher. The number of pairs in the comparisons is shown by the blue dashed line and the scale at the top. The mean difference is shown by the red line and the standard deviation of the differences by the solid blue lines (Ho et al., 2010a).

vich, 1998a,b; Gorbunov and Kornblueh, 2001; Ao et al., 2003; Sokolovskiy, 2001, 2003; Beyerle et al., 2004, 2006 and Wickert et al., 2004. To a large extent they have been resolved by advanced radio-holographic (or wave optics) inversion methods (e.g. Gorbunov, 2002) and open-loop tracking (e.g. Sokolovskiy, 2001).

In PLL tracking, the phase of the RO signal is modeled (projected ahead) by extrapolation from the previously extracted phase (Stephens and Thomas, 1995; Sokolovskiy, 2001; Ao et al., 2003; Beyerle et al., 2006). The PLL cannot reliably track the RO signal to the surface due to rapid fluctuations in phase and amplitude (caused by multipath propagation) that are not adequately modeled by the tracking loop. This causes significant tracking errors that may include biases in the retrieved bending angles and refractivities in the lower troposphere, and finally in the loss of lock, resulting in the insufficient penetration of the retrieved profiles. In addition, PLL tracking cannot be used to track rising occultations in the troposphere. 


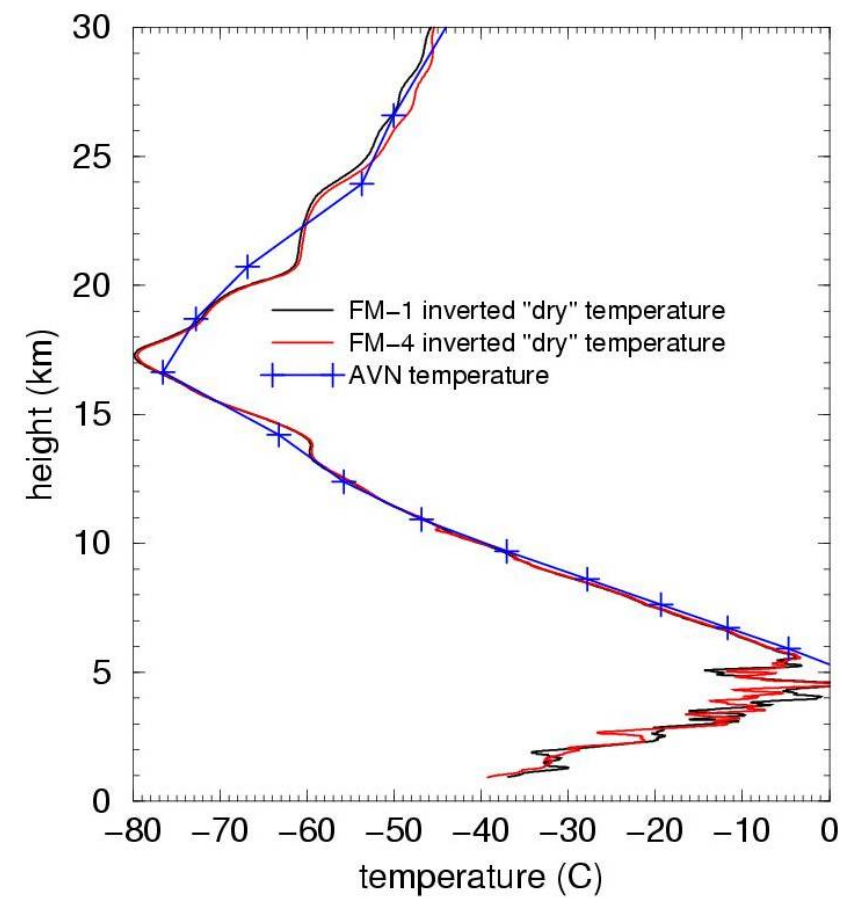

Fig. 7. Two different profiles of "dry temperature" obtained from Flight Module 1 (FM-1) and Flight Module 4 (FM-4) near $20.4^{\circ} \mathrm{S}$ $95.4^{\circ} \mathrm{W}$ on 23 April 2006, eight days after the launch of COSMIC when the spacecraft were very close together. AVN is a sounding from the NCEP global forecast system analysis interpolated to the location of the COSMIC soundings (source: UCAR CDAAC).

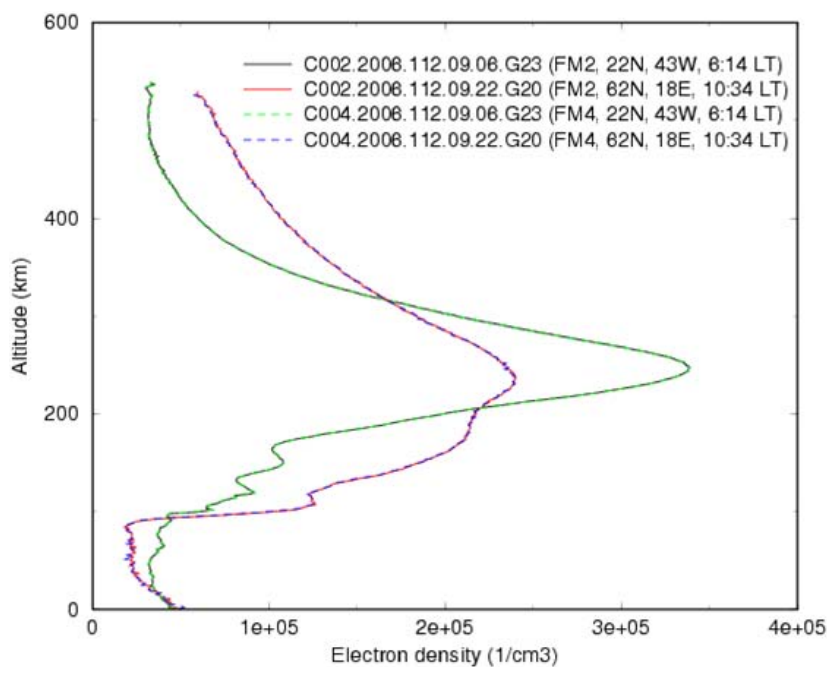

Fig. 8. Two pairs of different profiles of electron density obtained from FM-2 and FM-4 on 22 April 2006, seven days after launch when the spacecraft were very close together. FM-2 and FM-4 were within $30 \mathrm{~km}$ of each other. At any given time, FM-2 was within $1 \mathrm{~km}$ of where FM-4 was $4 \mathrm{~s}$ later (source: UCAR CDAAC).

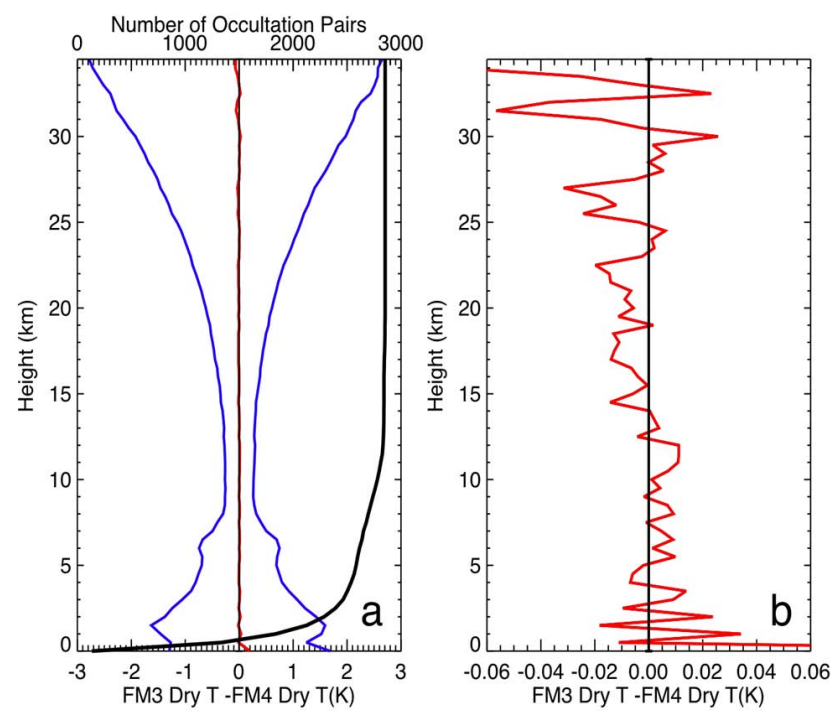

Fig. 9. Statistics showing "dry temperature" differences between two nearby COSMIC Satellites (FM-3 and FM-4) within $10 \mathrm{~km}$ of each other: (a) mean difference (red line near center), standard deviation of the differences (blue lines) and number of pairs of data (black line); (b) enlarged view of mean differences. The statistics indicate no significant bias difference between the two instruments on different platforms and a precision of $0.02-0.05 \mathrm{~K}$ at all levels (Ho et al., 2009a).

To overcome these problems, a model-based open-loop (OL) tracking technique was developed for use in the moist troposphere for both setting and rising occultations (Sokolovskiy, 2001). In OL tracking the receiver model does not use feedback (i.e., the signal recorded at an earlier time), but it is based instead on a real-time navigation solution and an atmospheric bending angle model.

The model-based OL technique allows tracking complicated RO signals under low SNR (signal to noise ratio), tracking both setting and rising occultations, and penetration of the retrieved profiles below the top of the ABL. The OL tracking was implemented successfully for the first time by JPL in the SAC-C RO receiver in 2005 (Sokolovskiy et al., 2006a). OL tracking is being routinely applied for the first time on COSMIC (Sokolovskiy et al., 2009; Ao et al., 2009). Figure 5 shows the improvements in OL compared to PLL tracking in retrievals in the lower troposphere using SAC-C data.

A significant improvement in the wave optics inversion methods was achieved with the application of suitable integral transforms to the whole complex (phase and amplitude) RO signals (Gorbunov, 2002; Jensen et al., 2003, 2004; Gorbunov and Lauritsen, 2004). These methods convert the RO signal from the time coordinate to the impact parameter representation, which allows, under the assumption of spherical symmetry of refractivity, complete resolution of the multipath propagation by obtaining bending angle as a singlevalued function of impact parameter. 


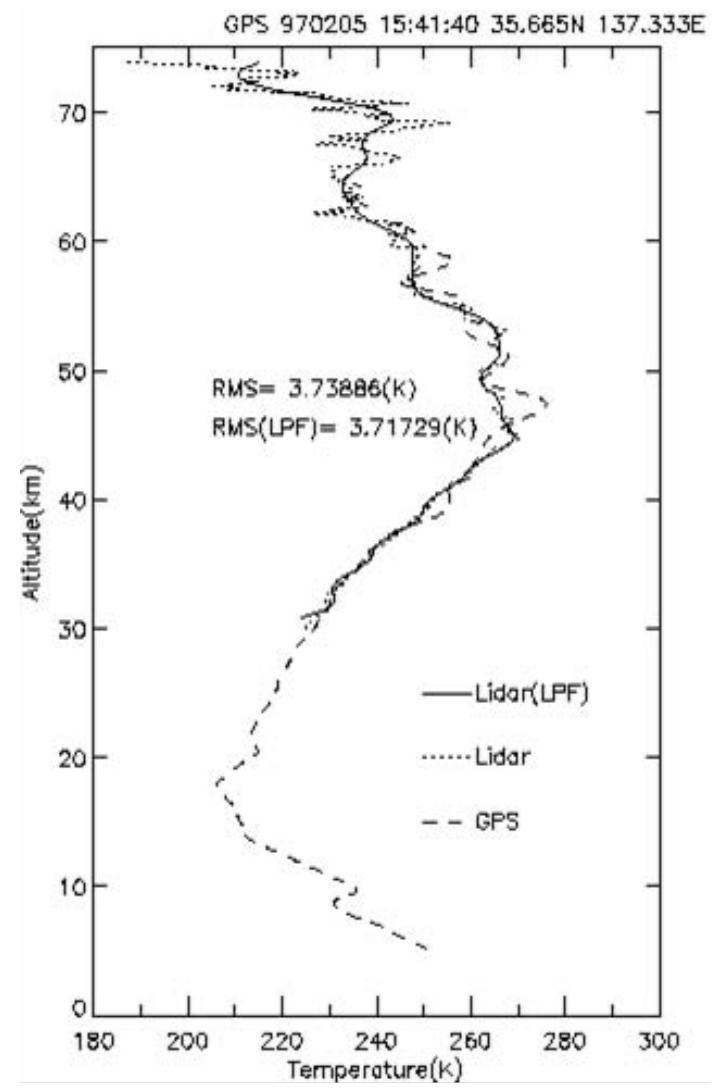

Fig. 10. Comparison of temperature profiles between GPS/MET data (dashed lines) at 15:41 UTC, 5 February 1997 at $35.7^{\circ} \mathrm{N}$, $137.3^{\circ} \mathrm{E}$ and Rayleigh lidar data (dotted line) between 15:08 and 16:26 UTC at $36.1^{\circ} \mathrm{N}, 140.1^{\circ} \mathrm{E}$ (Tsuda et al., 2000).
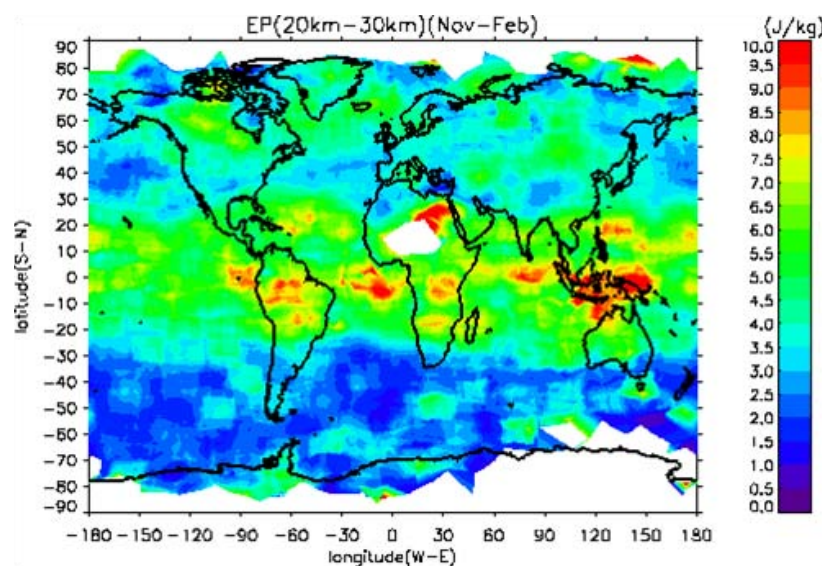

Fig. 11. Gravity wave climatology computed from GPS/MET data during November-February in 1996 and 1997. Colors depict potential energy (EP) between 20 and $30 \mathrm{~km}$ for NovemberFebruary 1996-1997. Warm colors show maximum gravity wave activity as deduced from the GPS/MET vertical temperature profiles. These areas generally coincide with regions of deep convection in the troposphere (Tsuda et al., 2000).

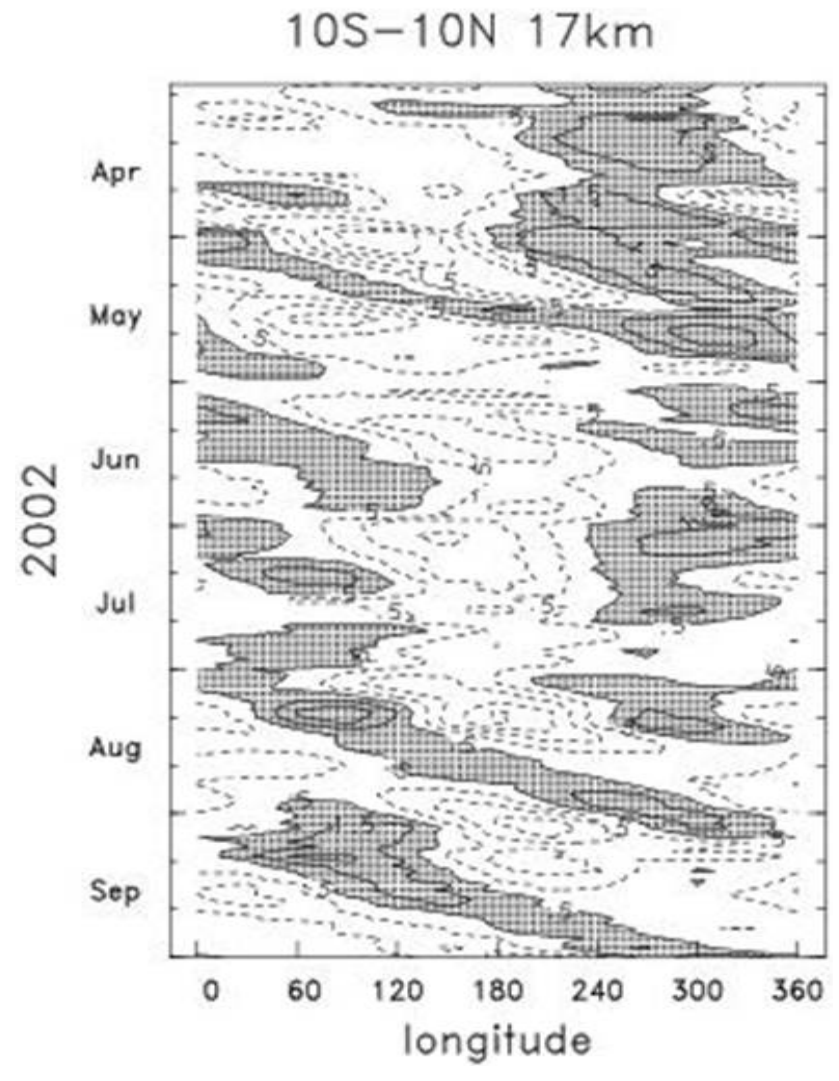

Fig. 12. Kelvin wave variability near the equatorial tropopause observed in CHAMP GPS radio occultation measurements. Longitude-time diagrams of zonal wave numbers 1-2 temperature variations over $10^{\circ} \mathrm{N}-10^{\circ} \mathrm{S}$ during April-September 2002. Patterns indicate eastward propagating Kelvin waves. Contours are $0.5,1.5$, and $2.5 \mathrm{~K}$ (Randel and $\mathrm{Wu}, 2005$ ).

The high theoretical accuracy and precision of RO observations has been thoroughly demonstrated using $\mathrm{RO}$ observations from different missions. The accuracy has been determined through comparisons with independent observations (high-quality radiosondes and dropsondes) and highresolution analyses, such as those done by the European Centre for Medium-Range Weather Forecasts (ECMWF). However, a numerical estimate of the accuracy is difficult to determine by comparison with other independent observations, since the RO accuracy may well be greater than any other temperature observing system. Ho et al. (2010a) compared more than 5000 COSMIC RO dry temperatures with one of the most accurate radiosondes, Vaisala-RS92, and found a mean bias difference of $-0.01 \mathrm{~K}$ and a mean absolute bias difference of $0.13 \mathrm{~K}$, suggesting that the accuracy of RO dry temperatures is better than $0.13 \mathrm{~K}$ between 10 and $200 \mathrm{hPa}$ (Fig. 6). A similar result was found by Gobiet et al. (2007) and He et al. (2009).

The precision has been demonstrated by comparing nearby RO soundings from different instruments and satellites 

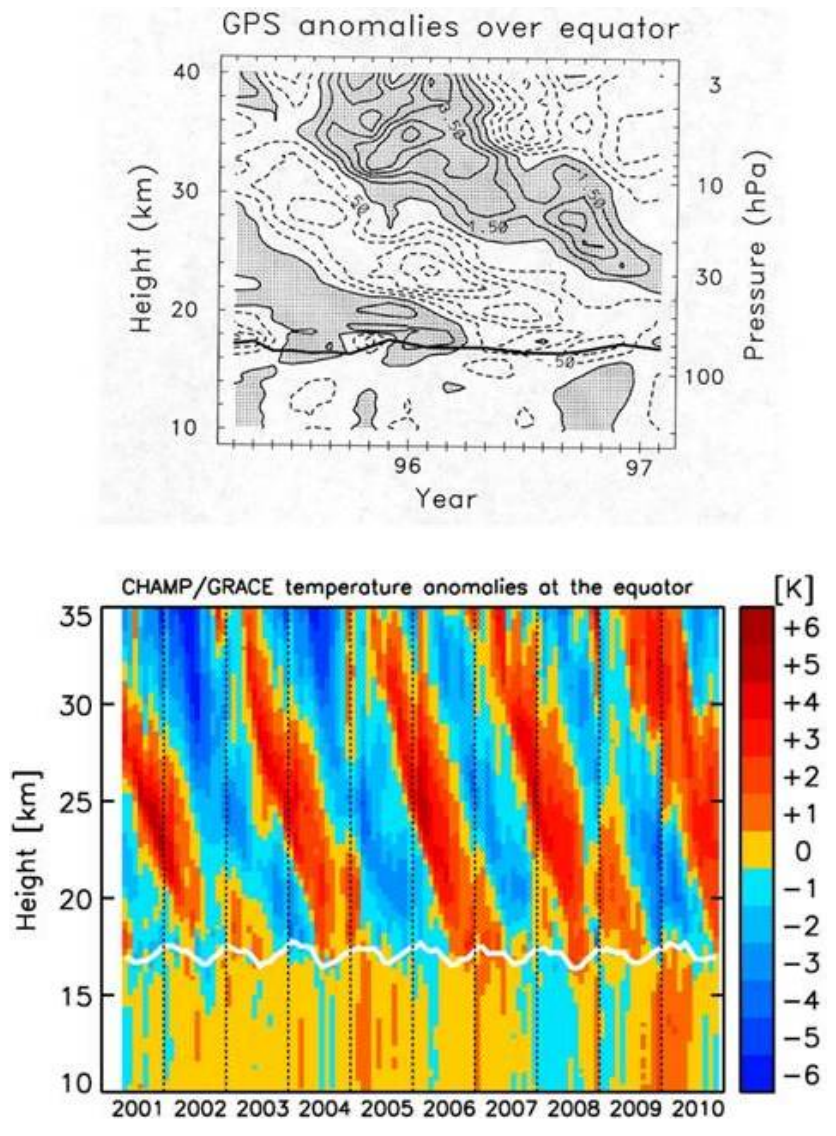

Fig. 13. (a top) Height-time series of deseasonalized temperature anomalies over the equator $\left(4^{\circ} \mathrm{N}\right.$ to $\left.4^{\circ} \mathrm{S}\right)$ derived from GPS/MET data. Contours are $+/-0.5,1.5,2.5, \ldots . \mathrm{K}$. Heavy line is cold point tropopause. Downward propagating patterns over the depth of the stratosphere with an approximate 2-yr periodicity reflect the stratospheric QBO (Randel et al., 2003). (b bottom) same as (a) above but for $5^{\circ} \mathrm{N}$ to $5^{\circ} \mathrm{S}$ using CHAMP data (T. Schmidt, GFZ, personal communication, 2010).

\section{Polar summer tropopause}
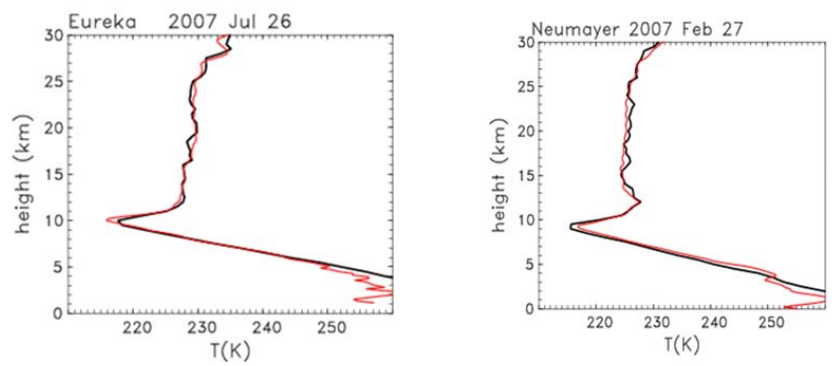

Fig. 14. COSMIC dry temperatures and high-resolution radiosonde temperatures showing sharp tropopauses at Eureka, Alaska $\left(80^{\circ} \mathrm{N}\right.$, $\left.86^{\circ} \mathrm{W}\right) 26$ July 2007 and Neumayer in Antarctica $\left(71^{\circ} \mathrm{S}, 8^{\circ} \mathrm{W}\right)$ 27 February 2007 (Randel and Wu, 2010).
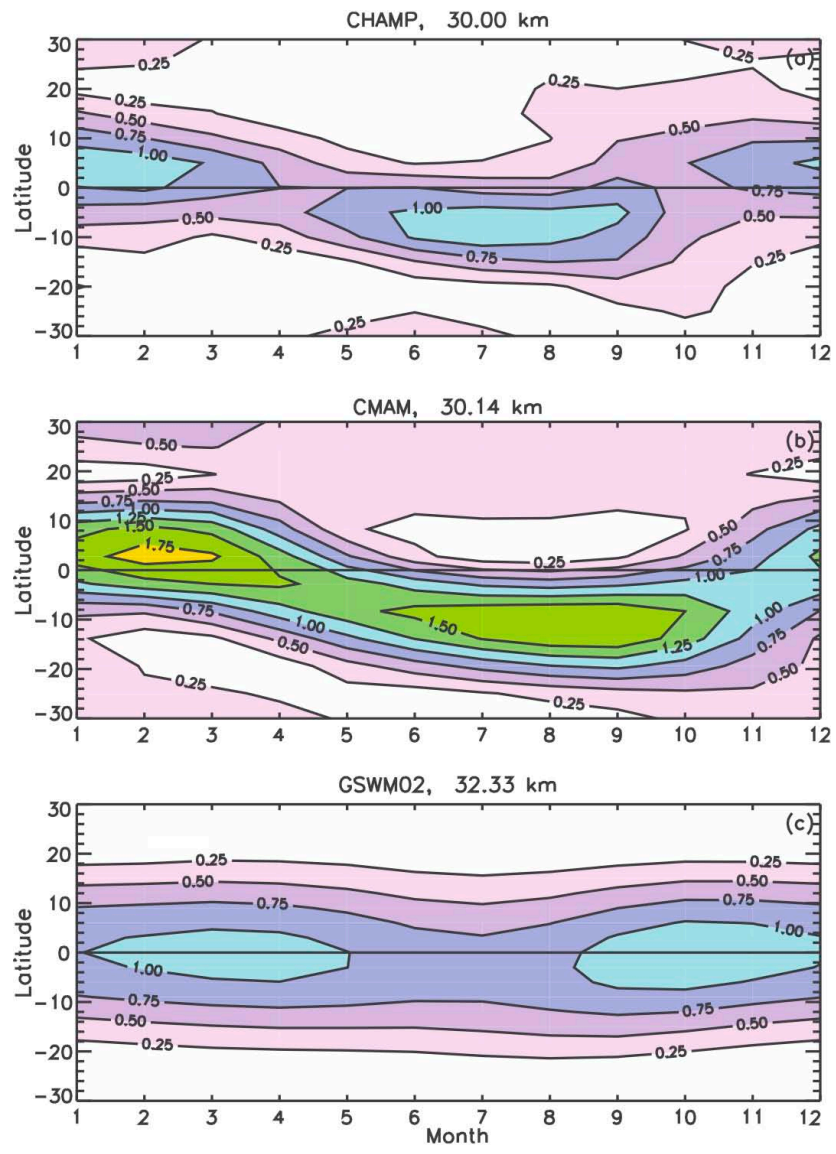

Fig. 15. Amplitudes of the diurnal tide near $30 \mathrm{~km}$ as a function of latitude and month from the (top) CHAMP RO observations (May 2001-August 2005) and (middle) Canadian Middle Atmosphere Model (CMAM) and (bottom) GSWM02 model simulations. The contour interval is $0.25 \mathrm{~K}$ (Zeng et al., 2008).

(Schreiner et al., 2007). Immediately after launch, the six COSMIC satellites were orbiting very close to each other at the initial altitude of $512 \mathrm{~km}$. The proximity of the satellites permitted a rare opportunity to obtain independent soundings very close (within tens of kilometers or less) to each other, allowing for estimates of the precision of the RO sounding technique. Figures 7 and 8 show the remarkable similarities of independent RO retrievals of "dry temperature" in the troposphere and stratosphere, and electron density in the ionosphere, respectively. "Dry temperatures" are computed from the observed refractivity under the assumption that water vapor pressure is zero in Eq. (1); the difference between "dry" temperature and actual temperature is due to the presence of water vapor. These retrievals were obtained a week after launch from two different COSMIC satellites located within $30 \mathrm{~km}$ horizontally, a few seconds, and a few hundred meters of orbit height of each other. Quantitative comparison of many pairs of soundings (Fig. 9) indicates that the precision of RO observations is better than $0.05 \mathrm{~K}$ (Ho et al., 2009a). 

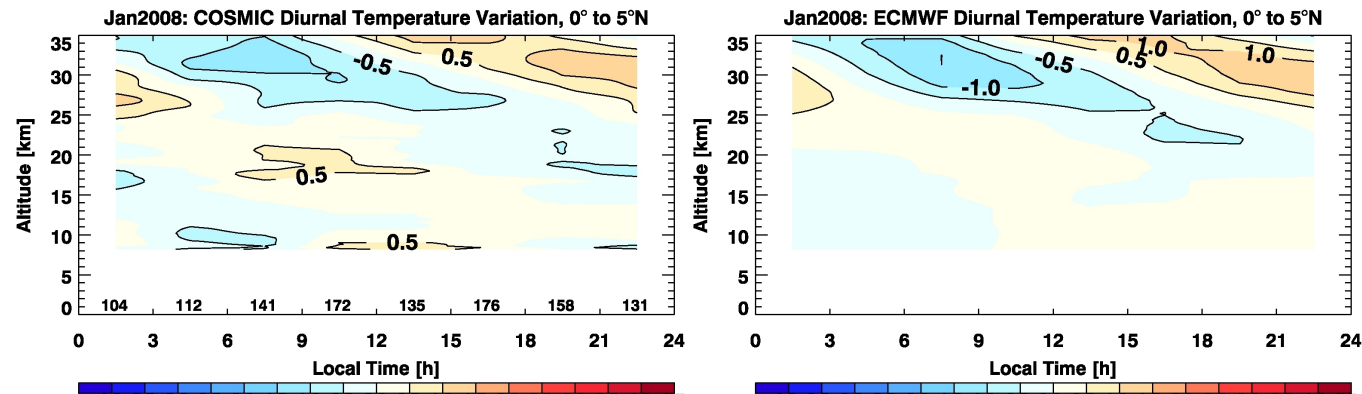

Fig. 16. COSMIC data show the diurnal tide near the equator (left panel) which compares well with the ECMWF tides (right panel). Poleward of about 50 degrees the sampling density is too small and natural variability swamps the diurnal signal (Pirscher et al., 2010).
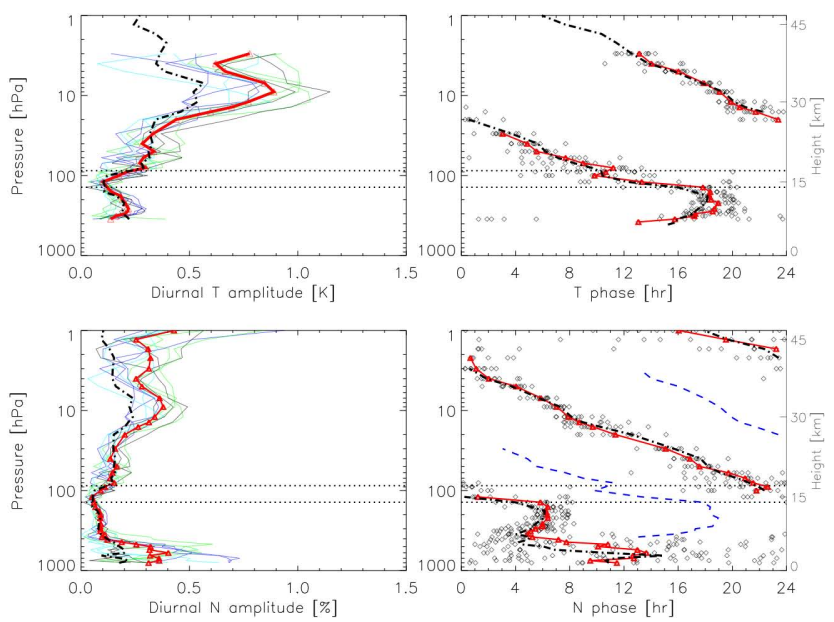

Fig. 17. Vertical structure of temperature and refractivity amplitudes (left panels) and phases (right panels) of diurnal variations over $10^{\circ} \mathrm{S}-10^{\circ} \mathrm{N}$ based on COSMIC RO observations in 2007. Each solid line in the left panels represents one monthly mean amplitude profile whereas phases from the monthly data are shown as open diamond in the right panels. The four seasons are denoted by different colors, e.g., DJF (green), MAM (blue), JJA (cyan), SON (black). The RED thick lines show the annual median values. The blue dashed lines in the lower right panel represent the temperature phase as shown in the upper right panel. The black dash-dot lines in all four panels correspond to the annual median-averaged results in 2007. The two black thin dashed lines in each panel mark altitudes at $14 \mathrm{~km}$ and $17 \mathrm{~km}$, respectively (Xie et al., 2010).

Similarly, Foelsche et al. (2011) found that refractivity and temperature climate records from multiple RO satellites were consistent within $0.05 \%$.

\section{Results from RO missions}

Many studies have demonstrated the power of RO to observe atmospheric phenomena for research, numerical weather prediction, benchmark climate observations, and space weather/ionospheric research and operations.
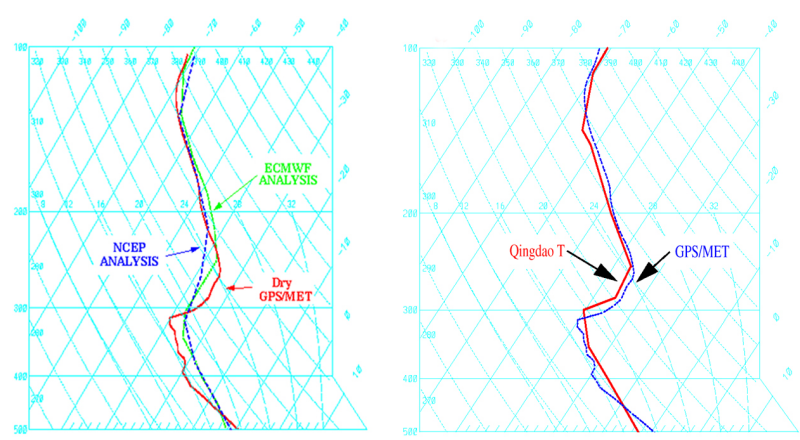

Fig. 18. A GPS/MET sounding through an upper-level front 00:55 UTC 22 October 1995 over China compared to soundings from NCEP and ECMWF (left panel) and a nearby radiosonde at Qingdao (right panel) (Kuo et al., 1998).

\subsection{Weather phenomena}

Starting with GPS/MET, RO observations have been used in case studies of atmospheric phenomena, such as gravity waves, fronts, tropopause structures, the ABL, and tropical cyclones.

\subsubsection{Stratospheric waves and tropopause}

The first sounding of Earth's atmosphere from GPS/MET showed a wave-like structure in the temperature profile between 25 and $35 \mathrm{~km}$ in the lower stratosphere (Fig. 1). At first it was not clear whether this was a real feature or not, but many subsequent soundings showed similar structures that proved to be manifestations of real gravity waves of various types (Tsuda et al., 2000; Steiner and Kirchengast, 2000). Figure 10 shows a comparison of a GPS/MET sounding with lidar measurements. Such soundings were used to create a gravity wave climatology, which showed maximum gravity wave activity over regions of deep tropical convection (Fig. 11). Randel et al. (2003) used GPS/MET data averaged over time and space to resolve a variety of propagating waves in the stratosphere, including Kelvin waves, 

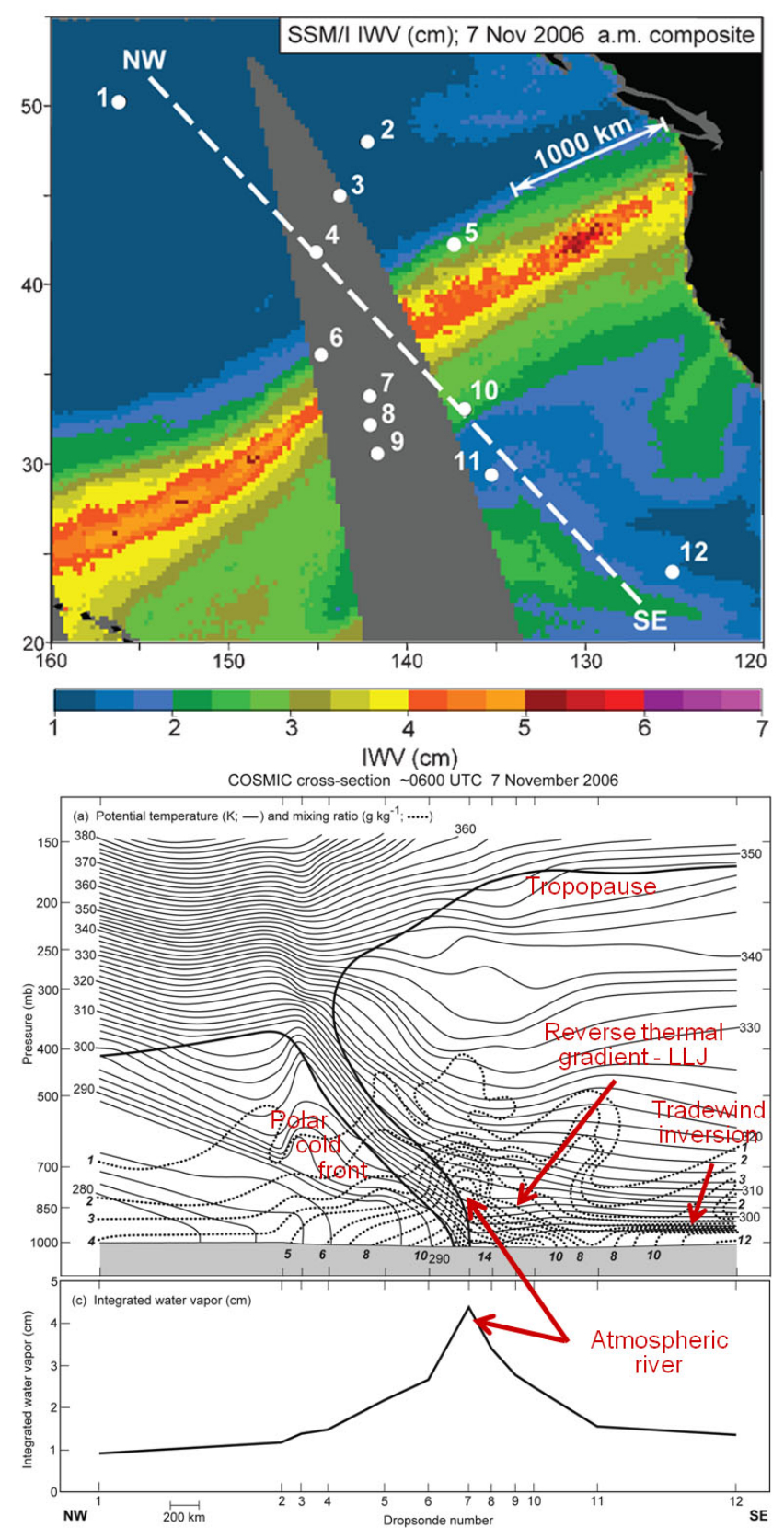

Fig. 19. Cross section of potential temperature $(\mathrm{K})$ and mixing ratio $\left(\mathrm{g} \mathrm{kg}^{-1}\right)$ perpendicular to a front and associated atmospheric river, 7 November 2006, based on COSMIC observations only (Neiman et al., 2008).

mixed Rossby-gravity waves, and waves associated with the Quasi-Biennial-Oscillation (QBO), as shown in Figs. 12 and 13a (Randel et al., 2003; Randel and Wu, 2005). Schmidt et al. (2005) used CHAMP and SAC-C data to further study the QBO and now have a nine-year record of the QBO (Fig. 13b).

The high vertical resolution of RO observations and the fact that they are most accurate in the upper-
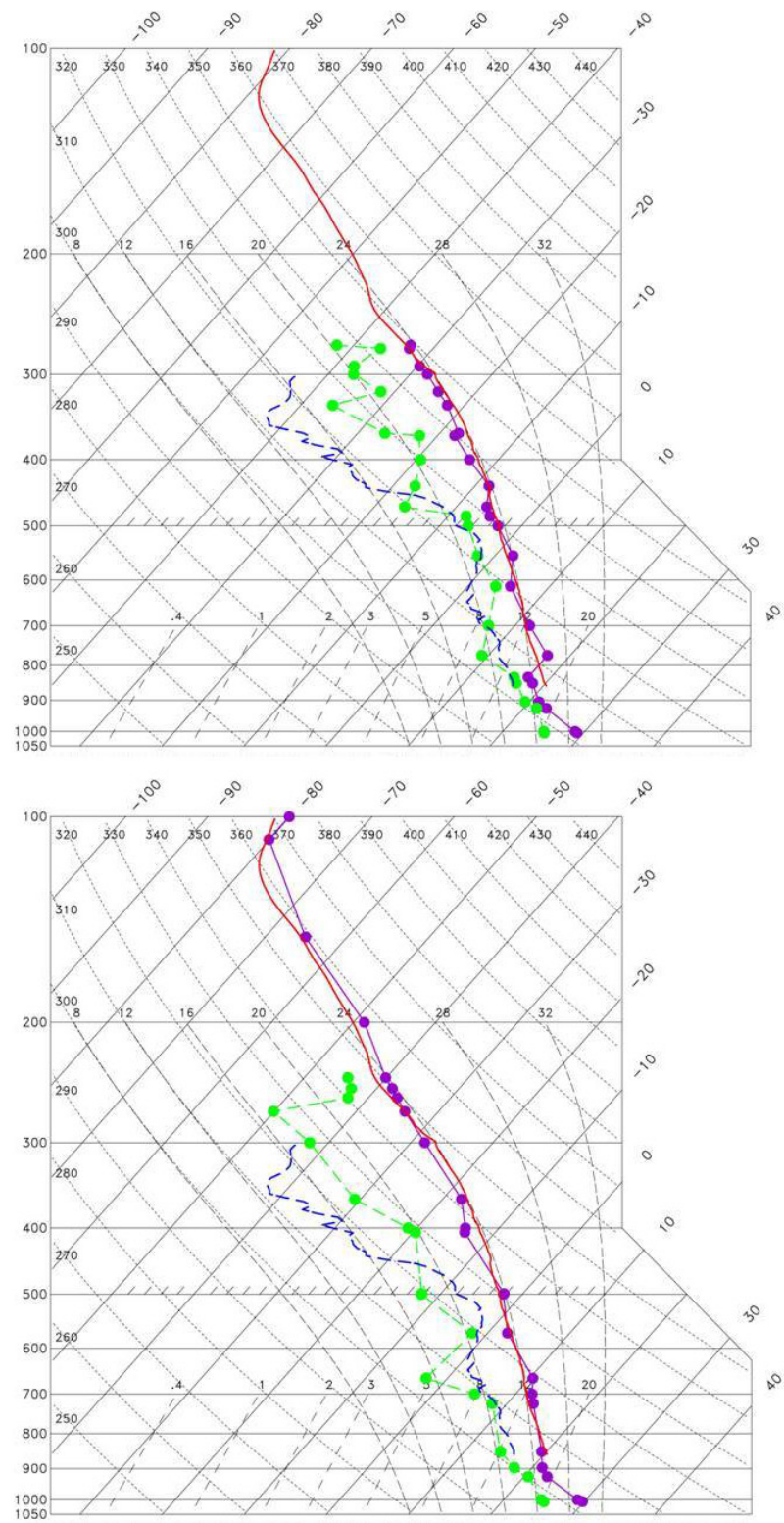

Fig. 20. CHAMP soundings compared to two radiosondes in Typhoon Toraji (2001). The CHAMP temperature and water vapor profiles are computed from the observed refractivity and a 1D-VAR algorithm (Anthes et al., 2003).

troposphere/lower stratosphere (UTLS) make them an ideal observational tool for studying the tropopause and related UTLS phenomena (Borsche et al., 2007; Schmidt et al., 2008, 2010; Steiner et al., 2009). Figure 14 (Randel and Wu, 2010) shows the ability of RO observations to resolve very sharp tropopauses with a vertical resolution similar to that of high-resolution radiosondes. 

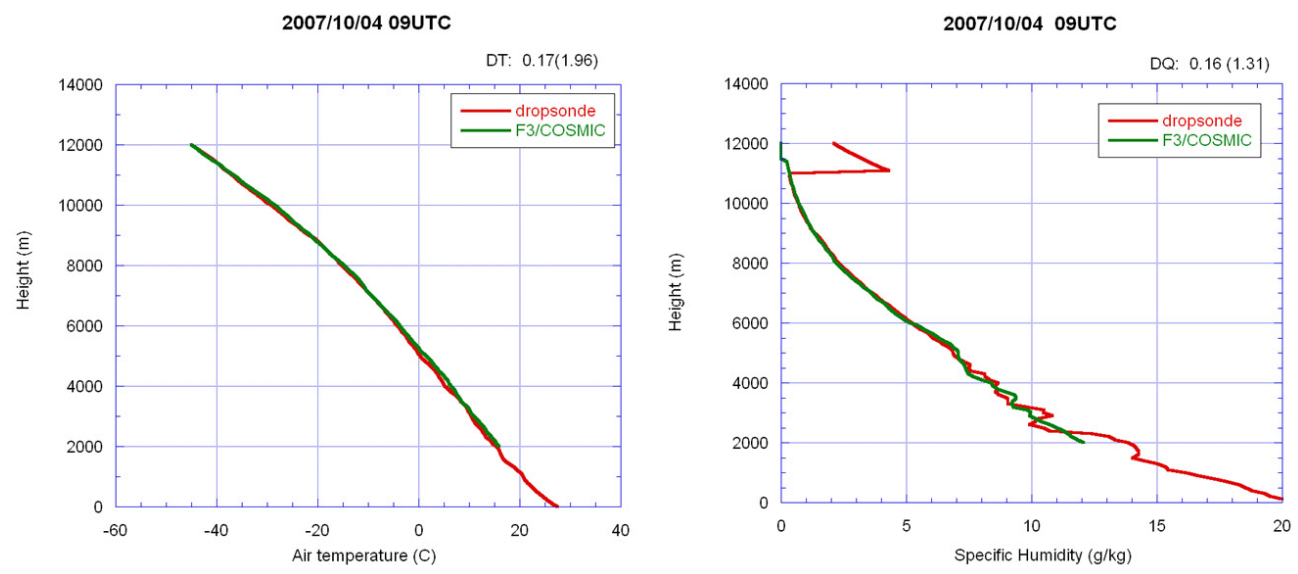

Fig. 21. Comparison of FORMOSAT-3/COSMIC atmospheric retrieval profile (green) with high-resolution in-situ dropsonde data (red). Left panel: temperature $\left({ }^{\circ} \mathrm{C}\right)$. Right panel: specific humidity $\left(\mathrm{g} \mathrm{kg}^{-1}\right)$ (source: Po-Hsiung Lin, National Taiwan University, 2010).

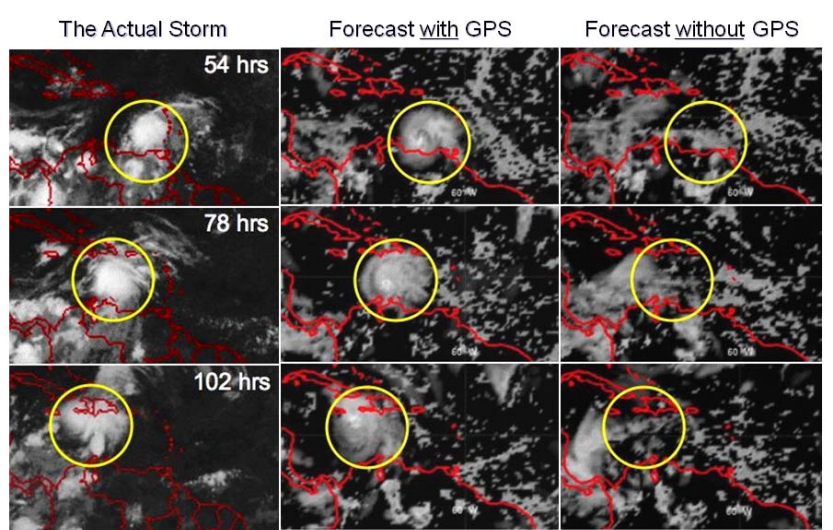

Fig. 22. Forecasts of tropical cyclone Ernesto (2006) using the NCAR WRF (Weather Research and Forecast) model. Images on the left are actual satellite photos of the event. Images on the right were generated from a forecast made without RO data, while the images in the center are from a forecast that assimilated $15 \mathrm{RO}$ profiles. The elapsed time since the beginning of the forecast is shown on the left-hand images - in this case, 54, 78 and $102 \mathrm{~h}$ (Liu et al., 2011).

\subsubsection{Diurnal tides}

The diurnal variation of temperature, water vapor and many atmospheric phenomena, driven by solar heating, is a fundamental aspect of Earth's weather and climate. RO observations can be used to study propagating and trapped vertical waves associated with diurnal solar forcing. Zeng et al. (2008) used CHAMP data between May 2001 and August 2005 to show for the first time that RO observations could be used to analyze the structure of migrating diurnal tides. Figure 15 shows the amplitudes of the diurnal tide near $30 \mathrm{~km}$ as a function of latitude and month from the CHAMP RO observations and the CMAM (Canadian Middle Atmosphere Model, Fomichev et al., 2002) and GSWM02

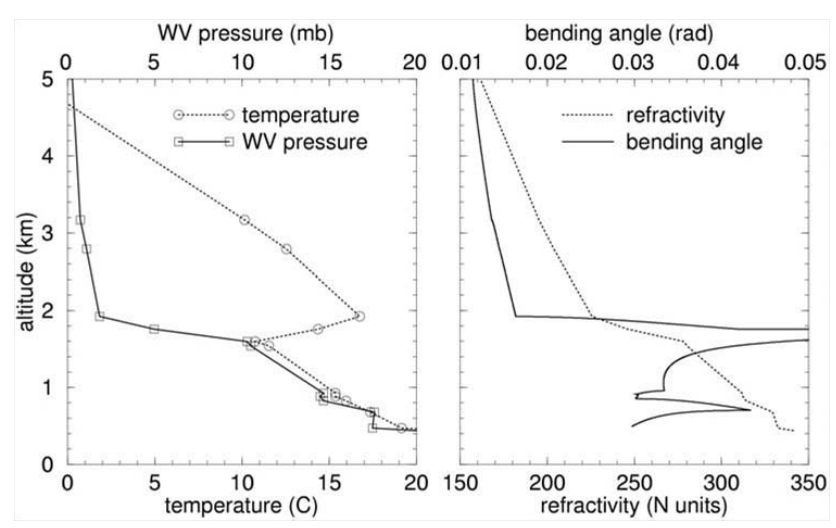

Fig. 23. Temperature $\left({ }^{\circ} \mathrm{C}\right)$ and water vapor pressure (mb) (left) and corresponding bending angle and refractivity (right) profiles associated with a well-defined ABL. The bending angles reach a sharp maximum at the top of the ABL, which is characterized by large vertical gradients of temperature and water vapor (Sokolovskiy et al., 2007).

(Global-Scale Wave Model Version 2; Hagan and Forbes, 2002, 2003) model simulations.

The single satellite CHAMP orbit required 130 days to sample the full diurnal cycle. More recently, Pirscher et al. (2010) and Xie et al. (2010) used COSMIC observations to study diurnal tides (Figs. 16 and 17). The six satellites associated with COSMIC were able to sample the diurnal cycle globally within one month.

\subsubsection{Atmospheric fronts}

Although RO observations represent weighted averages over horizontal scales of approximately $300 \mathrm{~km}$, most of the information is contributed by the atmospheric properties in the inner $50 \mathrm{~km}$ of the footprint (Fig. 3); hence they are able to resolve horizontal gradients in temperature and water vapor 


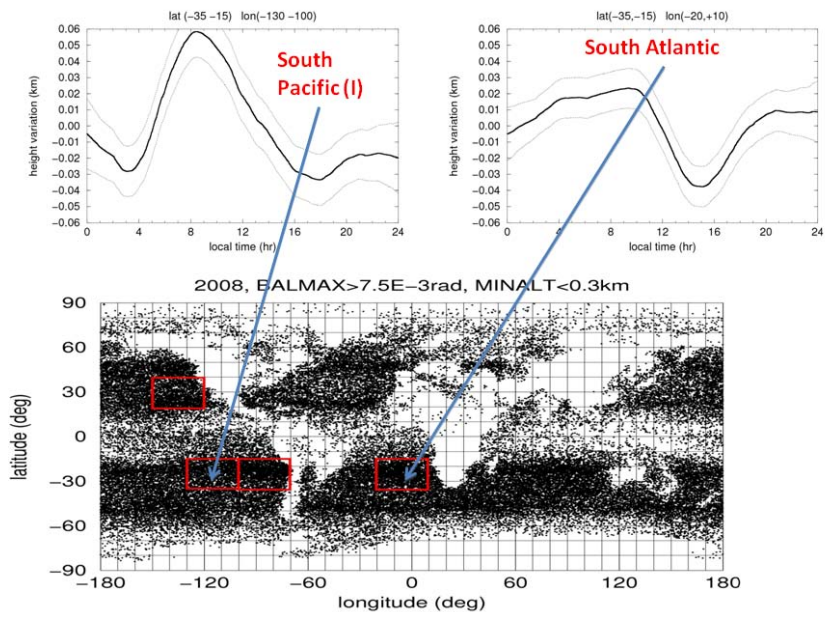

Fig. 24. Variability of the ABL depth over the oceans and some land areas in 2008 from COSMIC data (Sokolovskiy et al., 2010).

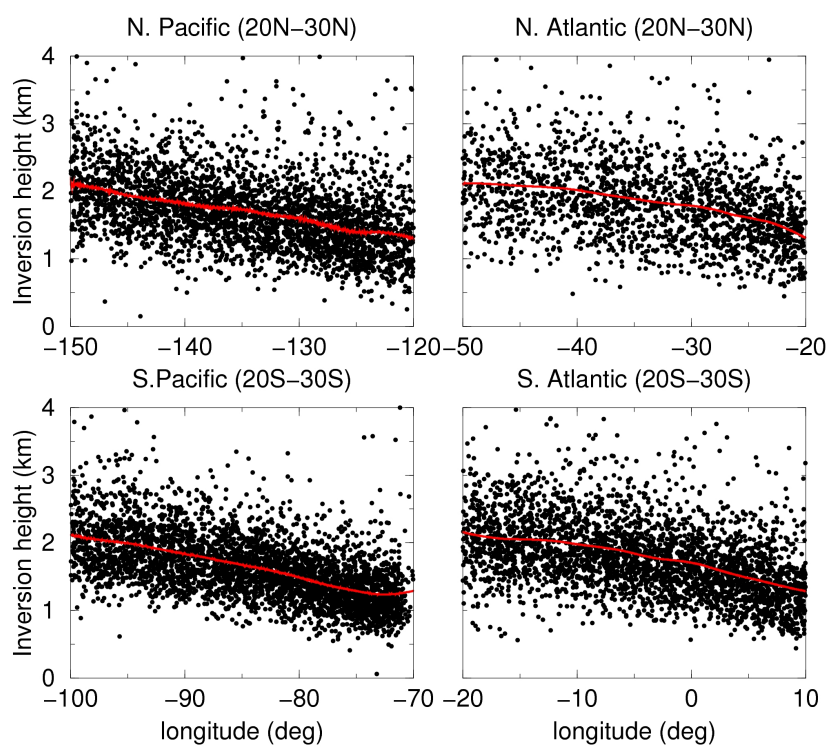

Fig. 25. Variation of the ABL top with longitude over the North and South Pacific and North and South Atlantic over a three-year period (2007-2009). Data constrained by strength of inversion layer defined by the vertical gradient in bending angle greater than $0.01 \mathrm{rad}$. Top left: North Pacific averaged between $20^{\circ} \mathrm{N}$ and $30^{\circ} \mathrm{N}$. Top right: North Atlantic averaged between $20^{\circ} \mathrm{N}$ and $30^{\circ} \mathrm{N}$. Lower left: South Pacific averaged between $20^{\circ} \mathrm{S}$ and $30^{\circ} \mathrm{S}$. Lower right: South Atlantic averaged between $20^{\circ} \mathrm{S}$ and $30^{\circ} \mathrm{S}$ (Sokolovskiy, 2010, personal communication. A similar figure was shown by Sokolovskiy et al., 2010).

associated with fronts. Figure 18 shows the vertical temperature profile associated with an upper-level front over China (Kuo et al., 1998). The National Centers for Environmental Prediction (NCEP) and ECMWF analyses show a highly smoothed version of the front in comparison to the

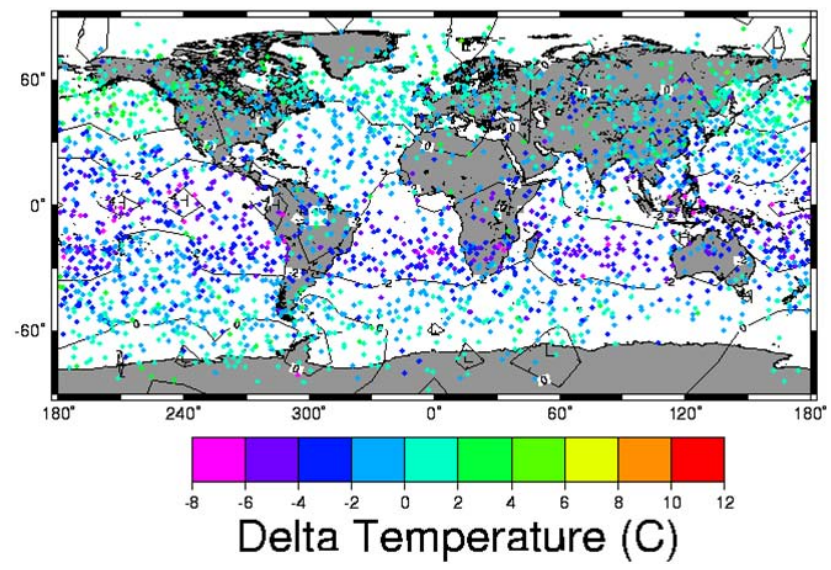

Fig. 26. GPS/MET minus NCEP-NCAR reanalysis temperatures $\left({ }^{\circ} \mathrm{C}\right)$ at $100 \mathrm{hPa} 6$ January-27 February 1997 . Note the systematic differences in the equatorial regions between GPS/MET and NCEP. NCEP is significantly warmer than GPS/MET in the equatorial regions and somewhat cooler in middle latitudes (Anthes et al., 2000).

GPS/MET sounding and a nearby radiosonde at Qingdao, which agree much more closely.

Figure 19 shows a horizontal cross section through a front and "atmospheric river" constructed from 12 COSMIC soundings located approximately perpendicular to the front (Neiman et al., 2008). The strong horizontal gradients in temperature and water vapor are resolved by the COSMIC observations.

\subsubsection{Tropical cyclones}

Tropical cyclones form and spend most of their lives over oceans, where observations of the moisture field assume critical importance in forecast models (Foley, 1995). RO observations are essentially unaffected by clouds and are, therefore, capable of sounding tropical cyclones. Their sensitivity to water vapor in the lower troposphere makes them very useful in initializing numerical models of tropical cyclones. Figure 20 shows a CHAMP sounding compared to two radiosondes in Typhoon Toraji on 29 July 2001 (Anthes et al., 2003). Figure 21 shows a comparison of two COSMIC soundings with high-resolution dropsondes in Typhoon Jangmi on 28 September 2008 (Po-Hsiung Lin, National Taiwan University, personal communication, 2010). The RO temperature and water vapor soundings were computed using a 1D-VAR technique as described in http://cosmic-io.cosmic. ucar.edu/cdaac/doc/documents/1dvar.pdf. The close agreement shows the capability of RO soundings to contribute information about the temperature and water vapor structure in typhoons. 


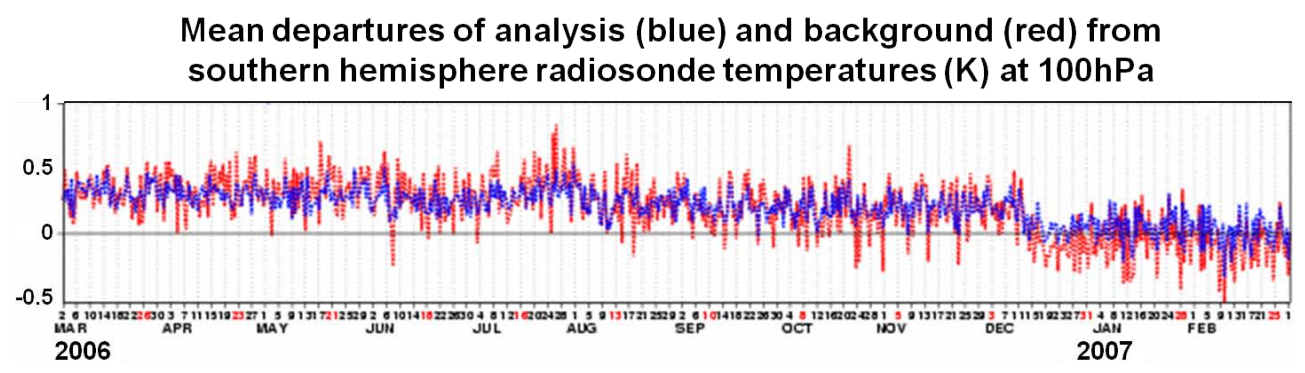

Fig. 27. Time series of the mean and standard deviations of the ECMWF background and analysis temperatures at $100 \mathrm{hPa}$ showing a reduction in the bias errors on 12 December 2006 when COSMIC data began to be assimilated (green arrow) (Luntama et al., 2008).

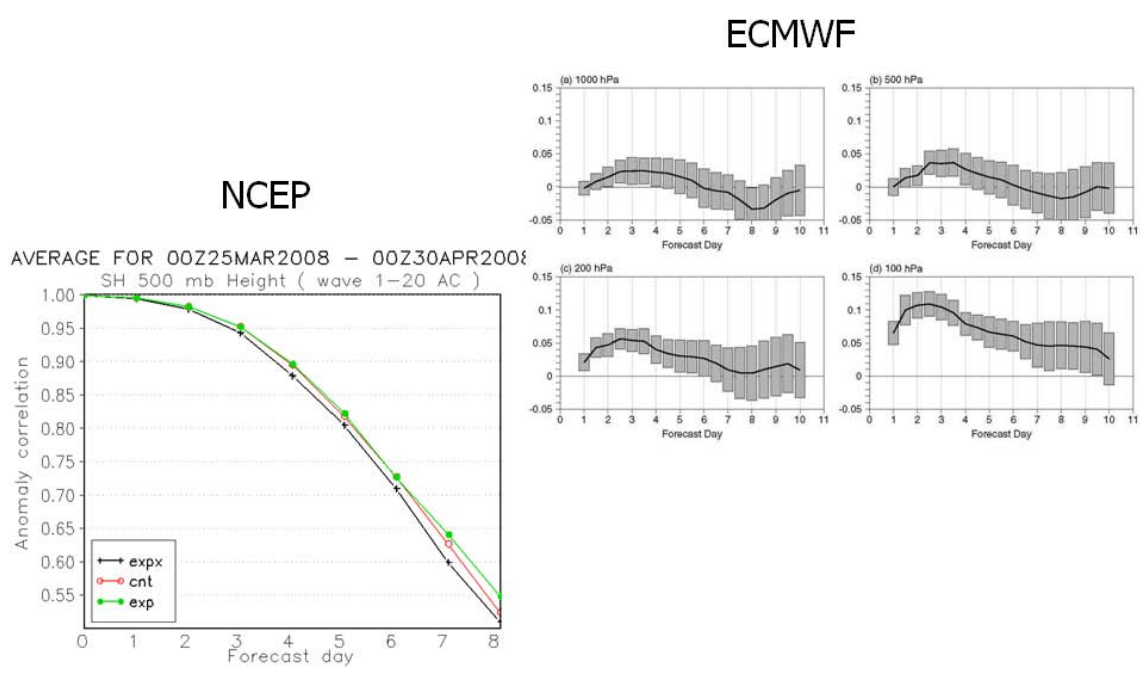

Fig. 28. Impacts of RO data in operational forecasts at NCEP (left, Cucurull, 2010) and the ECMWF (right, Healy, 2008). The NCEP data show the anomaly correlation for the 500-hPa height over the Southern Hemisphere in spring 2008. The use of COSMIC data adds $8 \mathrm{~h}$ to the forecast skill at day 4 and $15 \mathrm{~h}$ at day 7. The ECMWF data show the fractional reduction of the (a) 1000, (b) 500, (c) 200, and (d) $100 \mathrm{hPa}$ RMS temperature errors in the Southern Hemisphere, verified against radiosonde observations. Positive values represent improvement in terms of RMS errors. The vertical bars represent the $95 \%$ confidence interval. The COSMIC data reduced the fractional $100 \mathrm{hPa}$ temperature RMS errors by $11 \%$ for the 12 -h forecasts over the Southern Hemisphere, which is a large signal. The corresponding improvement in the standard deviation of the 12-h forecast errors was $5 \%$, showing that assimilating the RO measurements reduced both the random and systematic temperature errors.

The 1500-2000 COSMIC soundings per day do not provide enough horizontal resolution to adequately resolve the environment of tropical cyclones, yet occasionally they provide observations in critical locations that can make a large, positive impact on forecasts. Such a case occurred during the genesis of Hurricane Ernesto (2006). Liu et al. (2011) performed a set of five-day forecasts of Ernesto using the Weather Research and Forecast (WRF) model. In a forecast that did not use GPS observations, the WRF model was simply initialized from the NCEP operational global analysis at 06:00 UTC, 23 August to produce a five-day forecast. In the RO experiment, 15 COSMIC soundings collected during a 6$\mathrm{h}$ period from 03:00 UTC to 09:00 UTC, 23 August were assimilated into the initial fields. A five day deterministic forecast was then initialized from the updated ensemble mean analysis. Without assimilation of COSMIC data, the model failed to develop organized convection, and no tropical storm appeared in the model throughout the five day forecast period. Assimilating COSMIC soundings moistened the lower troposphere in the area of organized convection. The hurricane genesis process was simulated, and Tropical Storm Ernesto developed in the model, closely following that of the observed storm (Fig. 22).

Cucurull and Derber (2008) found that assimilating COSMIC observations in the NCEP operational model improved the temperature, water vapor, geopotential and wind fields. These results indicate that RO data will be useful in improving numerical forecasts of tropical cyclone genesis, especially if the number of occultations per day is increased significantly over the 1500-2000 that COSMIC provides. 


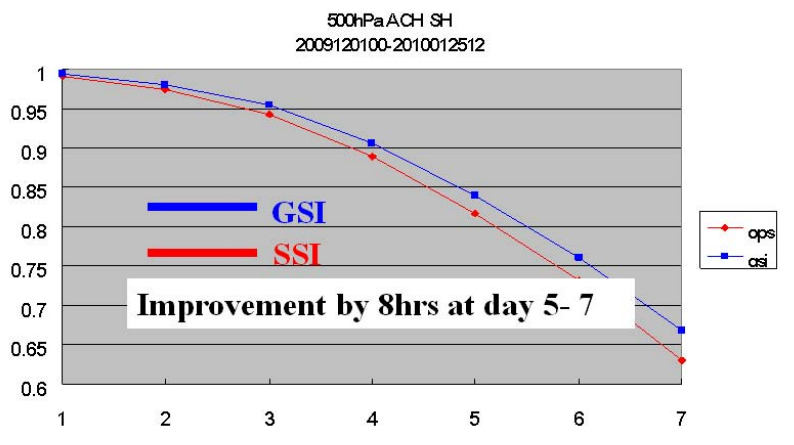

Fig. 29. Effect on forecast 500-hPa height anomaly correlation at the Central Weather Bureau (CWB), Taiwan during December 2009-January 2010 after COSMIC data were introduced. The significant, positive impact is produced by the improvement of RO data assimilation between SSI and GSI (Chin-Tzu Fong, Central Weather Bureau, personal communication, 2010).

\section{Profiling the atmospheric boundary layer}

The atmospheric boundary layer (ABL) connects the atmosphere with Earth's surface. The boundary between this turbulently mixed layer and the stably stratified atmosphere above is characterized by a temperature inversion and a decrease of relative and absolute humidity, especially in the subtropics. The depth of the ABL is an important parameter for NWP and climate models.

$\mathrm{RO}$ is the only remote sensing technique from space that can profile temperature and water vapor in the ABL. Figure 23 shows an example of the radiosonde temperature and water vapor profiles in the case of a sharp top of the ABL and the corresponding calculated bending angle and refractivity profiles (Sokolovskiy et al., 2007). Commonly there is a thin transition layer at the top of the ABL, which is characterized by a large negative vertical gradient of refractivity. This gradient produces a significant increase in the bending angle, resulting in defocusing (reduction of mean amplitude) and multipath propagation (scintillation) below. These effects result in large tracking errors or loss of lock in RO receivers operating in PLL mode. Thus monitoring of subtropical and tropical ABL is difficult with PLL tracking, although the loss of signal by a PLL receiver was exploited using CHAMP data by von Engeln et al. (2005) as a proxy for the ABL top. With OL tracking, the sharp top of the ABL can be determined from the bending angle or refractivity profile (Sokolovskiy et al., 2006b, 2007).

RO observations may be used to develop ABL climatologies, such as the spatial and temporal variations of the ABL (von Engeln et al., 2005; Sokolovskiy et al., 2007, 2010; Ao et al., 2008; Ratnam and Basha, 2010). The CHAMP climatology agreed well with the ECMWF analyses over this period, especially over the oceans. Figure 24 shows the diurnal variation of the ABL over the South Pacific and South Atlantic oceans. The intertropical convergence zone (ITCZ) has significantly fewer occultations showing a well-defined top of the ABL; this is related to general upward motion and convection in the ITCZ. Some areas where few, sharp vertical gradients (e.g. the western equatorial Pacific) occur are regions of frequent cyclogenesis. This suggests that $\mathrm{RO}$ data can be useful for monitoring conditions favoring or accompanying tropical cyclogenesis.

Figure 25 shows the variation of the ABL top with longitude over the North and South Pacific and North and South Atlantic. Lower heights of the ABL occur toward the western coasts of North and South America and Africa.

\section{Numerical weather analysis and prediction}

RO observations with their high accuracy, precision and lack of bias make them valuable in improving meteorological analyses and forecasts. Not only do they contribute independent information that is complementary to other satellite and in-situ observations, their essential lack of bias actually improves the impact of other sensors that have biases (Healy, 2008).

GPS/MET data have been used to discover bias errors in NWP analyses. For example, Fig. 26 shows temperature errors at $100 \mathrm{mb}$ in the equatorial band of the NCEP/NCAR (National Center for Atmospheric Research) reanalyses (Kalnay et al., 1996). The reanalysis is several $\mathrm{K}$ too warm, between $30^{\circ} \mathrm{N}$ and $30^{\circ} \mathrm{S}$, compared to the RO observations. These errors were not present in a comparison between GPS/MET and the corresponding ECMWF analyses (Anthes et al., 2000).

When the ECMWF started to assimilate COSMIC observations on 12 December 2006, the impact of the RO observations and the operational analysis and forecasts were immediately obvious (Luntama et al., 2008). Figure 27 shows that on 12 December a long-standing bias in 100-mb temperatures in the Southern Hemisphere was immediately reduced to near zero by the bias-free RO observations.

Figure 28 shows the impact of COSMIC data on NCEP (Cucurull, 2010) and ECMWF (Healy, 2008) forecasts. At NCEP, the anomaly correlation for the forecast $500-\mathrm{mb}$ height shows an eight-hour gain in forecast accuracy at Day 4. The ECMWF chart shows an improvement in the Southern Hemisphere 100-mb temperatures out to Day Ten. Taiwan's Central Weather Bureau is also showing a significant, positive impact by assimilating COSMIC data (Fig. 29, ChinTzu Fong, Central Weather Bureau, personal communication, 2010). The improvement is eight hours in the five- to seven-day forecasts. Similar improvements have been noted in the Australian forecast system (LeMarshall et al., 2010).

Cardinali (2009a) used an adjoint based observation technique to quantify the relative contributions of different observing systems to the 24-h forecast accuracy. She found that RO data (COSMIC and CHAMP) ranked number five in positive impact of all the 24 observing systems used by the 


\section{Operational ECMWF system September to December 2008. Averaged over all model layers and entire global atmosphere.}

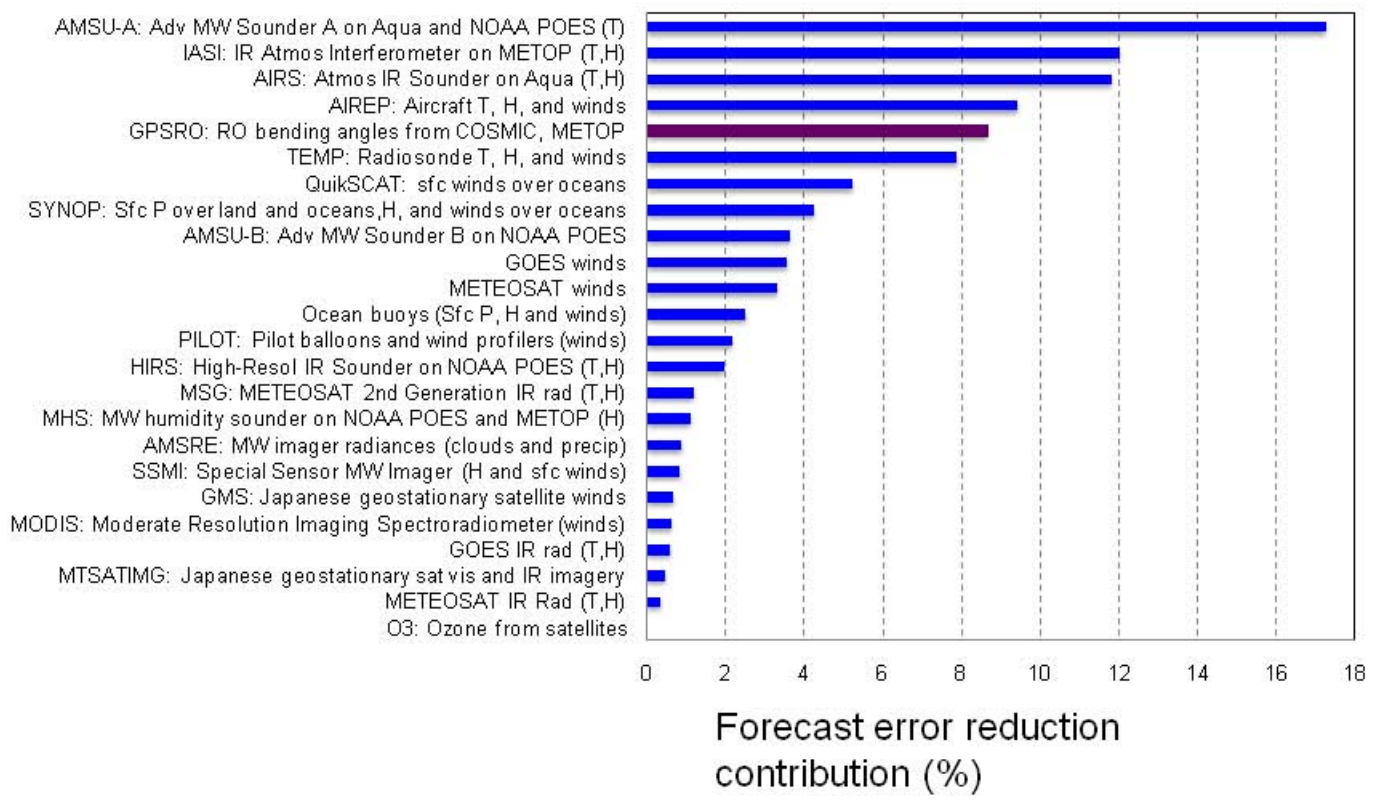

Fig. 30. Contribution to the reduction in forecast error (in percent) by all the observing systems used by the ECMWF. RO is the fifth most important observing system in reducing forecast error (Cardinali, 2009a, b).

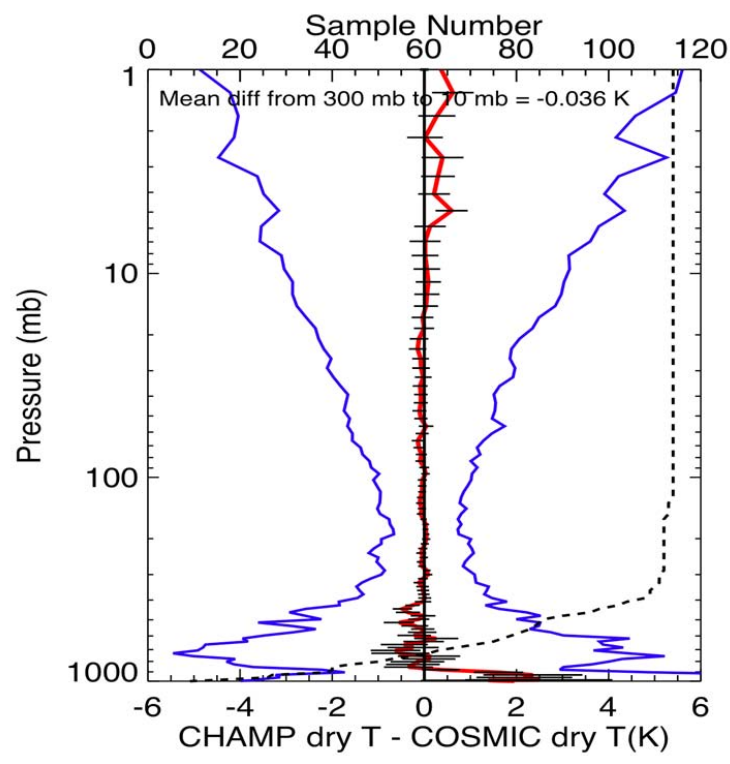

Fig. 31. Comparison of nearby (within $60 \mathrm{~min}$ and $50 \mathrm{~km}$ ) CHAMP (launched in 2001) and COSMIC (launched in 2006) dry temperature soundings showing that the retrieved soundings from the two different missions are comparable. The red line is the mean difference. The blue lines are the standard deviations, and the dashed black line is the number of pairs of data at each level. The mean bias is less than $0.05 \mathrm{~K}$ (Ho et al., 2009a).
ECMWF (Fig. 30; Cardinali, 2009b), reducing the forecast error by almost $9 \%$. This large impact occurred in spite of the fact that the number of RO observations amounted to only about $3 \%$ of the total number of observations assimilated by ECMWF.

\section{Climate applications}

Radio occultation observations are well suited for establishing a stable, long-term record required for climate monitoring (Goody et al., 1998; Steiner et al., 2001, 2009; Leroy et al., 2006a,b; Mannucci et al., 2006; Foelsche et al., 2008a, 2009; Wickert et al., 2009). In spite of the enormous importance of detecting climate trends, before RO there were no global atmospheric observing systems that could meet the stringent climate monitoring requirements of $0.5 \mathrm{~K}$ accuracy and better than $0.10 \mathrm{~K} \mathrm{decade}^{-1}$ stability (Ohring et al., 2005; Luntama et al., 2008). As shown above, RO observations meet these accuracy, stability and global sampling requirements.

Ringer and Healy (2008) showed that the signal of climate change over the coming decades should be clearly identifiable in radio occultation bending angle profile measurements. Their analysis of the predicted trends in bending angle in the tropics suggests that it might be possible to detect climate change signals within ten to sixteen years. Similar results were found by Leroy et al. (2006a) and Foelsche et 

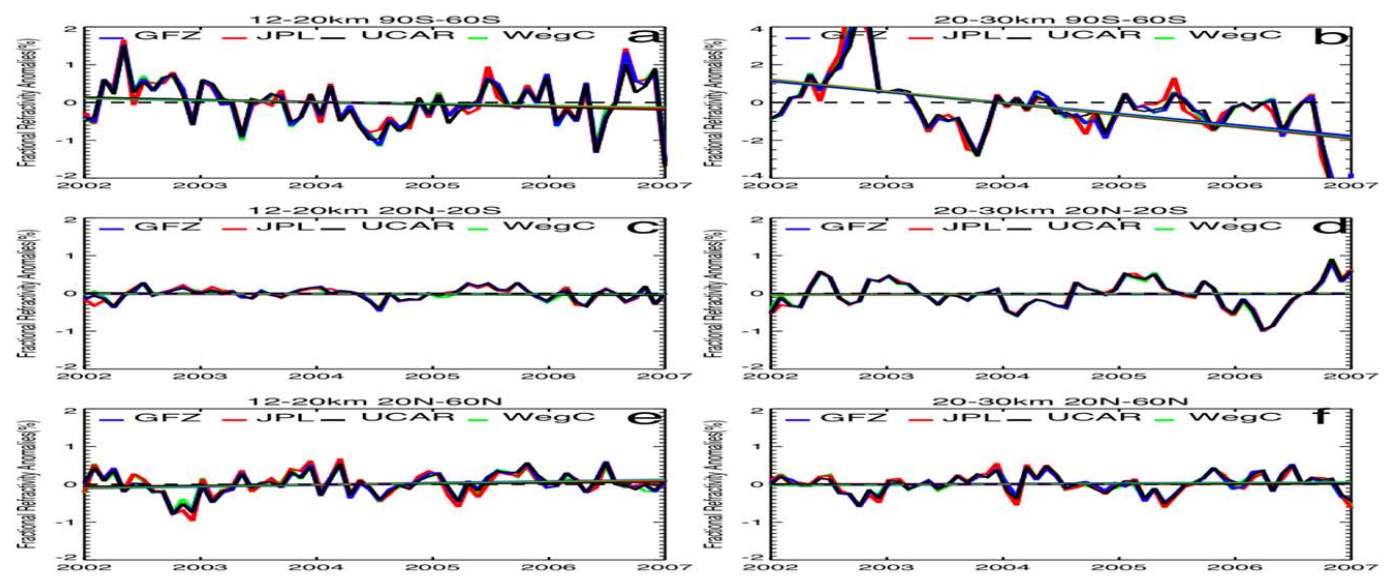

Fig. 32. Comparison of RO data (fractional refractivities) processed by four independent centers, GFZ (GeoForschungsZentrum, Potsdam), JPL, UCAR, and the Wegener Center (WegC) over the period 2002-2007. (a) 12-20 km, 90 $0^{\circ}-60^{\circ} \mathrm{S}$; (b) $20-30 \mathrm{~km}, 90^{\circ}-60^{\circ} \mathrm{S}$; (c) $12-20 \mathrm{~km}$, $20^{\circ} \mathrm{N}-20^{\circ} \mathrm{S}$; (d) $20-30 \mathrm{~km}, 20^{\circ} \mathrm{N}-20^{\circ} \mathrm{S}$; (e) $12-20 \mathrm{~km}, 20^{\circ} \mathrm{N}-60^{\circ} \mathrm{N}$; (f) $20-30 \mathrm{~km}, 20^{\circ} \mathrm{N}-60^{\circ} \mathrm{N}$ (Ho et al., $2009 \mathrm{c}$ ).
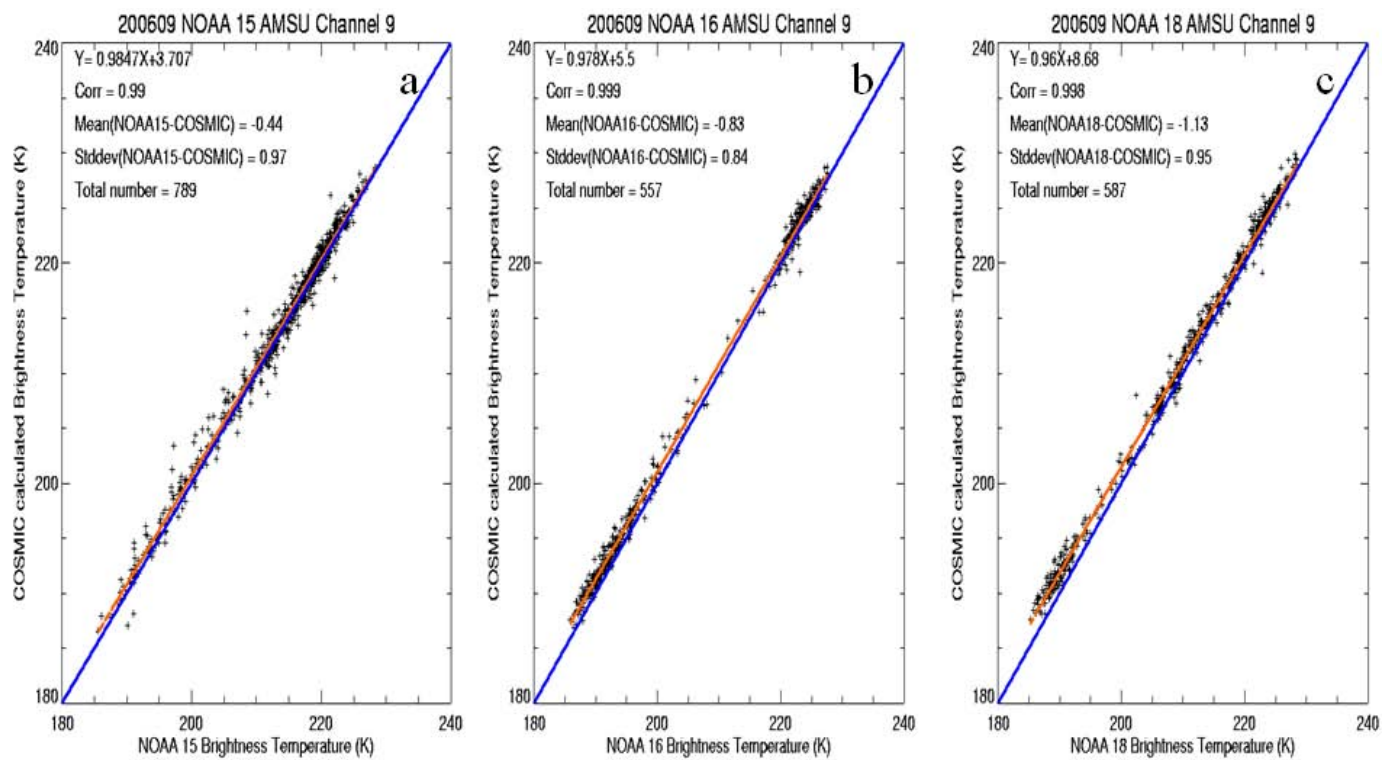

Fig. 33. Use of COSMIC data to calibrate AMSU on NOAA satellites. NOAA 15 brightness temperature (Tb) vs. COSMIC Tb (left); NOAA $16 \mathrm{~Tb}$ vs. COSMIC Tb (middle); and NOAA $18 \mathrm{~Tb}$ vs. COSMIC Tb (right). Units of Tb in K (Ho et al., 2009a).

al. (2008b) for other retrieved parameters, including geopotential height of pressure levels as a promising climate detection variable.

Although the temporal record of $\mathrm{RO}$ observations is relatively short (1995-present), Steiner et al. (2009) showed that the RO data can detect climate trends over this period. For example, they found a significant cooling of the lower stratosphere in February since 1995. Lackner et al. (2011) recently found, based on the RO climate record through 2010, a climate change signal in the geopotential height of pressure levels in the UTLS, consistent with tropospheric warming below.

\subsection{Mission and processing center independence}

RO observations are mission independent, implying that results from CHAMP, SAC-C, COSMIC or any RO mission can be compared directly to results from RO missions launched many decades from now. Figure 31 (Ho et al., 2009a) shows a comparison between two different missions, CHAMP and COSMIC. The mean bias difference is less than $0.05 \mathrm{~K}$, demonstrating the stability of RO observations. Foelsche et al. (2011) recently showed that for a three-year period the inter-satellite consistency of observations is within $0.03 \%$ for refractivity and $0.05 \mathrm{~K}$ for temperature, respectively. RO retrievals are also nearly independent of the center 


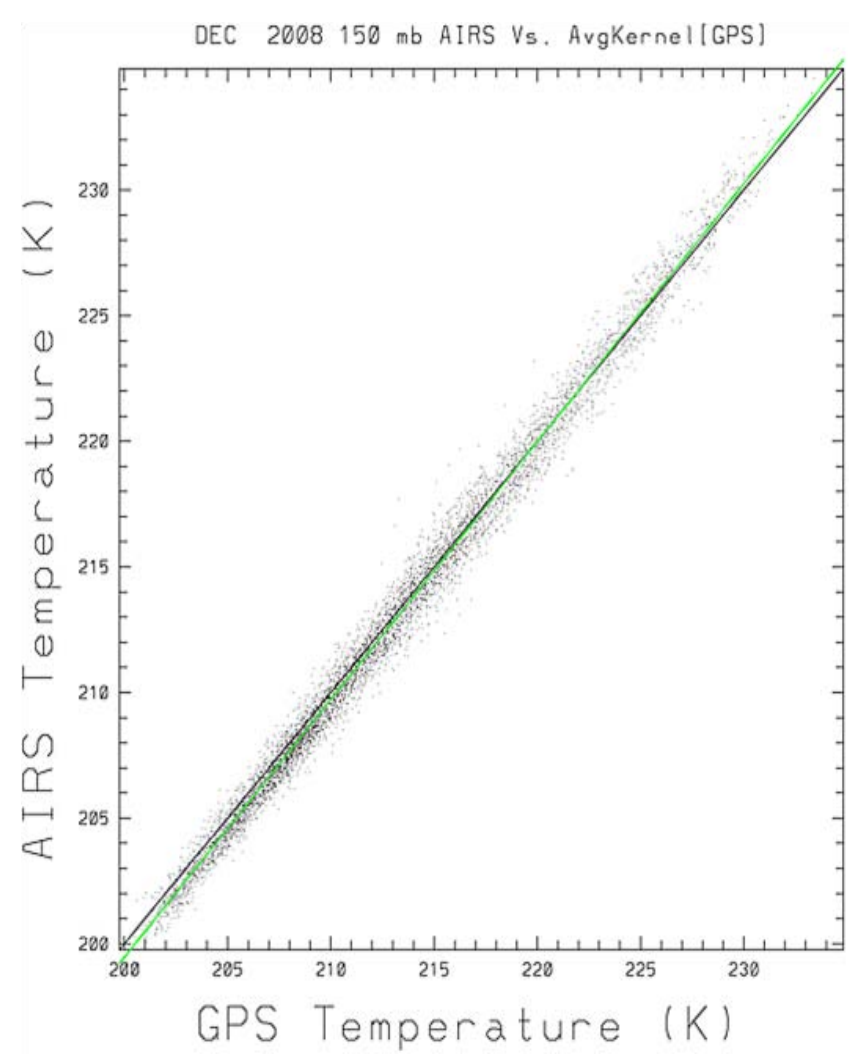

Fig. 34. Correlation of AIRS and COSMIC temperatures (K) at $150 \mathrm{hPa}$ for December 2008. AIRS temperatures are slightly lower (higher) than COSMIC temperatures for lower (higher) temperatures (Ho et al., 2010b).

that carries out the retrievals (Fig. 32, Ho et al., 2009c), another desirable property of climate benchmark observations. The small differences in Fig. 32 imply that the artificial "trends" associated with RO data processed by different centers is less than $0.03 \%$ per five years.

\subsection{Use of RO observations to calibrate other sounders}

Accurate, consistent and stable observations from different satellites are crucial for climate change detection. While RO observations can be used to establish a climate record by themselves, they can also be very useful to assess the quality of the observations from other sensors like the Microwave Sounder Unit (MSU) and Advanced MSU (AMSU) or infrared sounders. For example, Ho et al. (2007) found that the Channel 4 stratospheric retrievals in the Antarctic lower stratosphere in winter from both the Remote Sensing System (RSS) Inc. and the University of Alabama at Huntsville (UAH) were biased high relative to temperatures derived from RO measurements. Steiner et al. (2007) and Ladstädter et al. (2011) have found statistically significant differences in stratospheric-channel brightness temperature anomaly trends of the MSU and AMSU and RO from 2001 to 2009. This

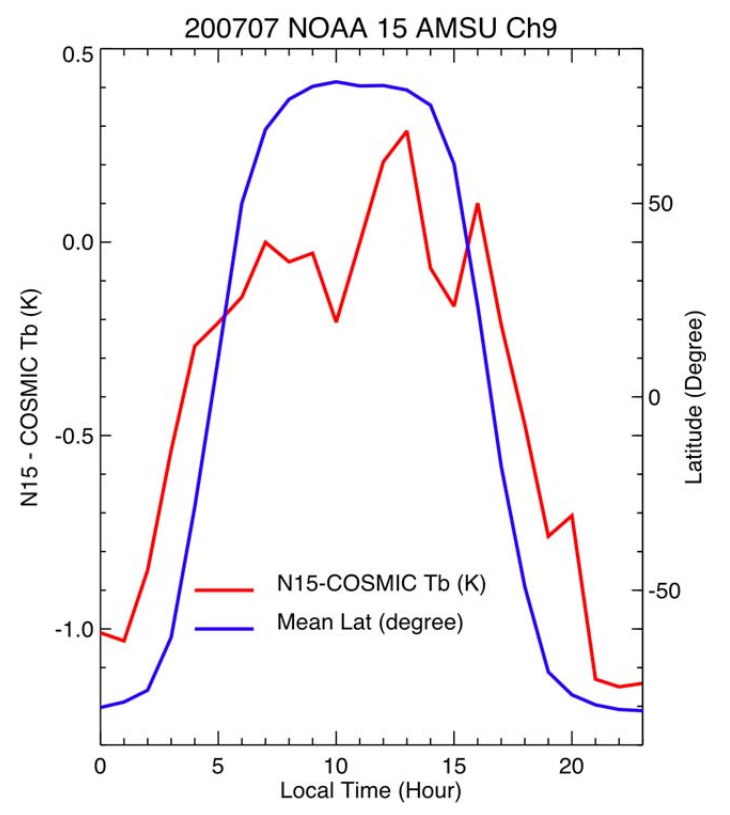

Fig. 35. NOAA-15 AMSU brightness temperatures (Tb) minus COSMIC Tb as a function of local time. Since the RO brightness temperatures are not affected by temperature variations of the satellites, the differences in Tb between the COSMIC and the NOAA-15 data are an indication of local-time biases in the NOAA-15 data. As shown in this figure, these differences follow a pattern similar to the mean latitude vs. local time (Ho et al., 2009b).

result points to the problem of long-term stability in the radiometric record.

COSMIC data have been used to inter-calibrate measurements from similar microwave sensors but on different satellites by converting COSMIC temperatures to equivalent AMSU Channel 9 brightness temperatures (Tb) and comparing these to the AMSU Tb from NOAA15 (N15) and NOAA18 (N18). The contribution of AMSU Channel 9 is mainly from the upper troposphere to the lower stratosphere (peak at $110 \mathrm{hPa}$ ). COSMIC temperature profiles are provided as input to an AMSU forward model to obtain the COSMIC equivalent $\mathrm{Tb}$. The comparisons are shown in Fig. 33 (based on Fig. 5 of Ho et al., 2009a).

Figure 33 shows that the synthetic COSMIC Tb values are highly correlated with those from NOAA satellites and with small standard deviations to the means. However, different orbits can cause small differences in sensor temperature owing to on-orbit heating/cooling of satellite components (Christy et al., 2003). This and other small differences between sensors and instrument drift can cause inter-satellite offsets that can be identified by the COSMIC $\mathrm{Tb}$. The close fit of COSMIC Tb to the NOAA satellite $\mathrm{Tb}$ demonstrates the usefulness of COSMIC data to calibrate microwave sounders. Similarly, RO observations can be used to validate infrared satellite data from both low-Earth orbiting (LEO) and geostationary satellites. Ho et al. (2010b) shows 

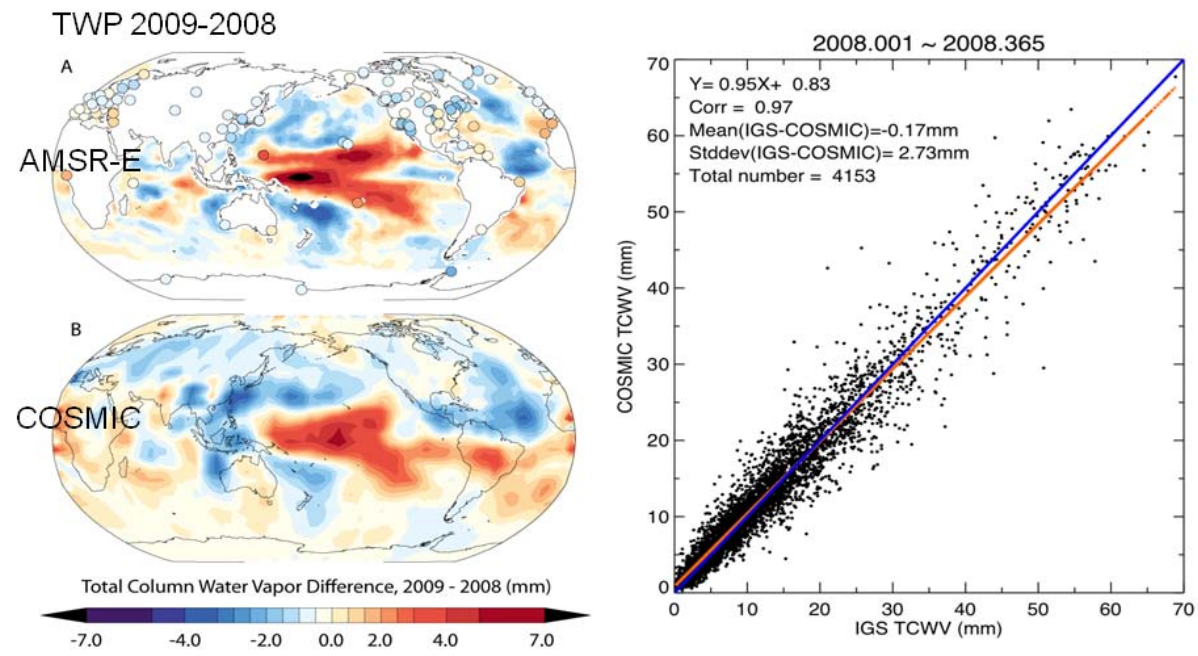

Fig. 36. Left: differences in precipitable water derived from AMSR-E and COSMIC soundings from 2008 to 2009. Warm colors indicate 2009 was wetter than 2008; cool colors indicate 2009 was drier than 2008 (Mears et al., 2010). Right: correlation of precipitable water in mm estimated from ground-based GPS (IGS TCWV) and COSMIC (COSMIC TCWV) (Ho et al., 2010a).

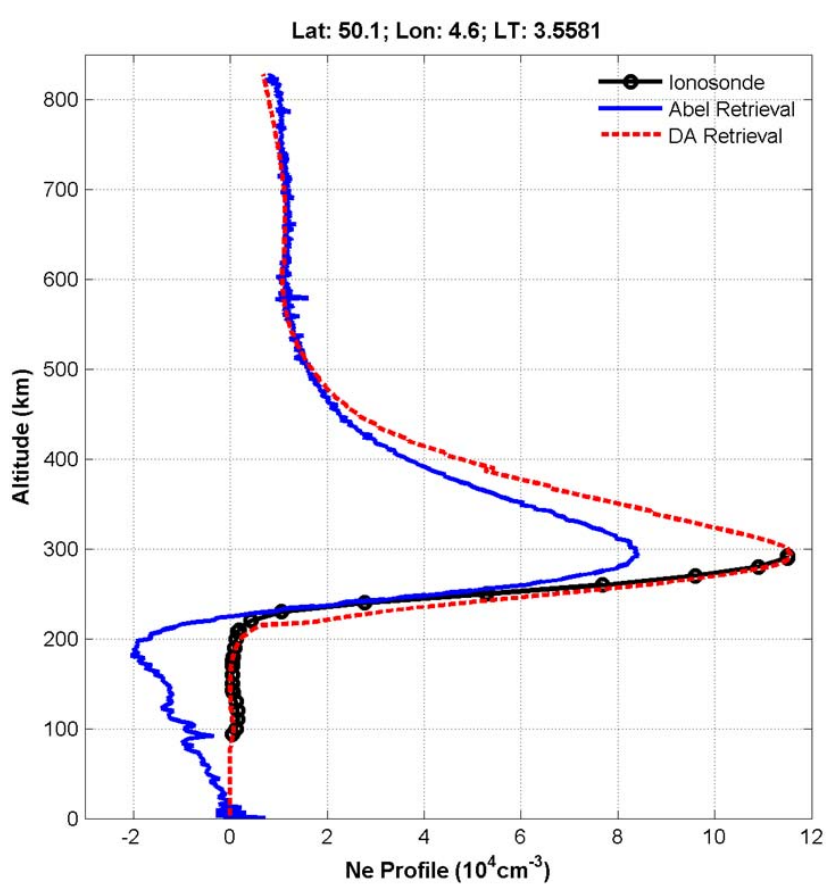

Fig. 37. An example of profiles of Abel and data assimilation retrievals of electron density $\left(\mathrm{Ne}\right.$ in $10^{4} \mathrm{~cm}^{-3}$ ) compared to a colocated Ionosonde-observed electron density profile (Yue et al., 2011).

how the COSMIC dry temperatures can be used to validate the Atmospheric Infrared Sounder (AIRS, Fig. 34).

Figure 35 (Ho et al., 2009b) shows how RO observations can be used to identify errors associated with diurnal heating and cooling effects on microwave satellite retrievals. The difference between the NOAA-15 brightness tempera-
Table 3. Space weather products produced by COSMIC (http://cdaac-www.cosmic.ucar.edu/cdaac/products.html).

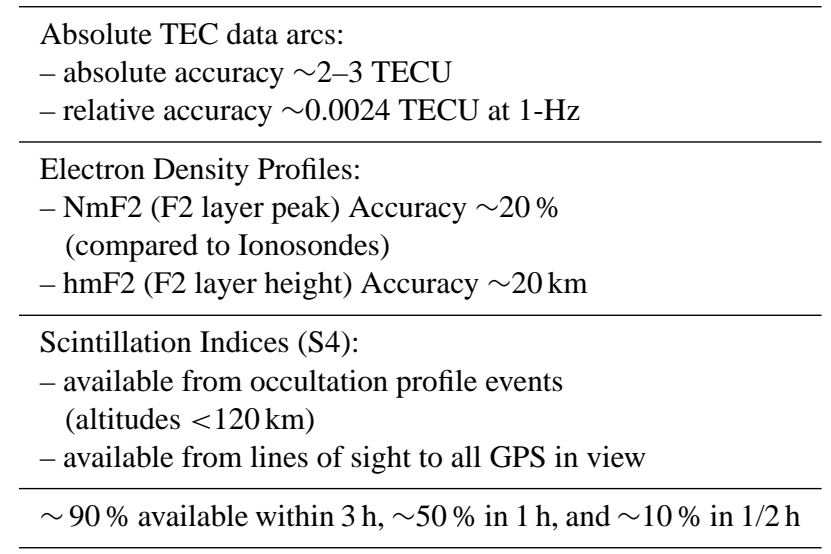

ture and the COSMIC brightness temperature is highly correlated with local time. Since the RO brightness temperatures are not affected by temperature variations of the satellites nor are they dependent on solar radiation, the differences in $\mathrm{Tb}$ between the COSMIC data and the NOAA-15 data are an indication of local-time biases in the NOAA-15 data. As shown in Fig. 35, these differences follow a pattern similar to the mean latitude vs. local time, and the NOAA-15 brightness temperatures show a variation of more than $1 \mathrm{~K}$ depending on the time of day.

COSMIC estimates of precipitable water have been compared with AMSR-E (Advanced Microwave Scanning Radiometer-EOS, a conically scanning passive microwave radiometer) as shown by Fig. 36 (Mears et al., 2010; Ho et al., 2010a). The two independent measurements are highly 

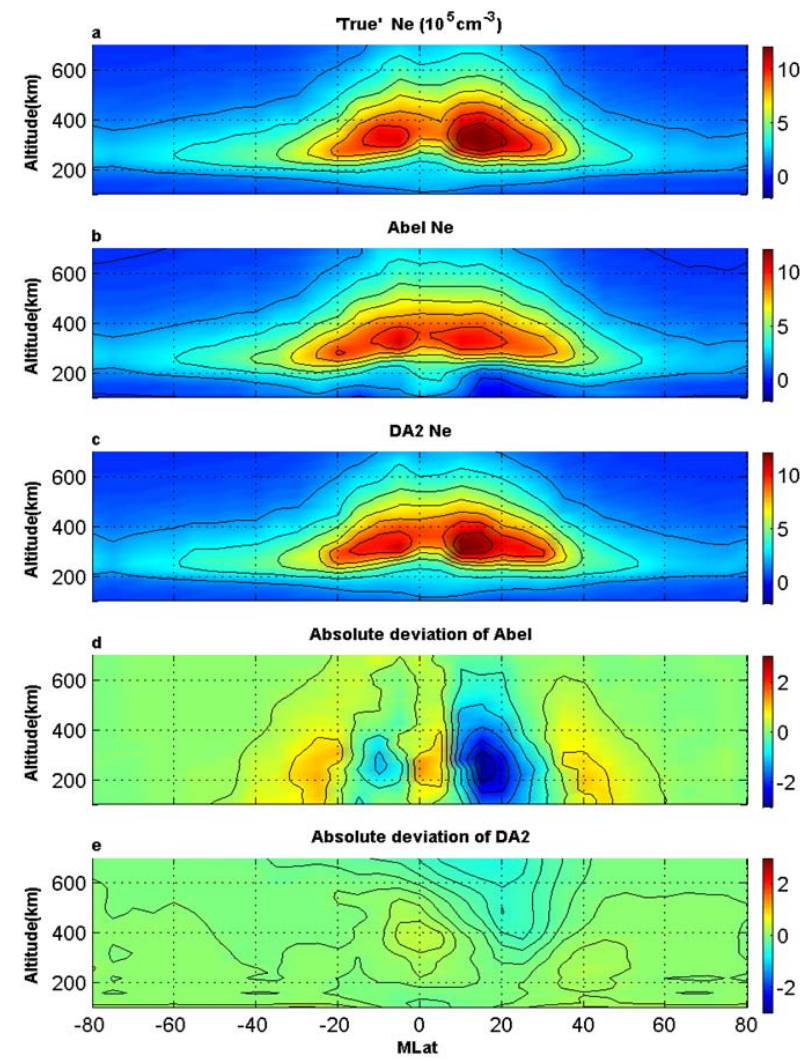

Fig. 38. Altitude-latitude cross sections of electron density ( $\mathrm{Ne}$ in $10^{5} \mathrm{~cm}^{-3}$ ) at midday (Local time LT $=13$ ). The top panel is the assumed "true" Ne cross section. The second and third panels from the top are the cross sections obtained from the Abel and data assimilation retrievals, respectively. The 4th and 5th panels from the top show cross sections of the errors associated with the Abel and data assimilation retrievals, respectively (Yue et al., 2011).

correlated and produce very similar climatologies. However, as shown in Fig. 36, AMSR-E and other passive radiometers are strongly limited over land due to difficulties with surface emissivities. This is not an issue with RO.

The above studies indicate that RO data can be used as a climate benchmark dataset. RO provides relatively uniform spatial/temporal coverage with an accuracy of approximately $0.1 \mathrm{~K}$ or higher, a precision of $0.05 \mathrm{~K}$ or better, and a satelliteto-satellite bias $<0.05 \mathrm{~K}$. RO retrievals are essentially independent of processing procedures and centers; the structural uncertainty from GPS RO data processed by different centers is less than $0.03 \%$ per $5 \mathrm{yr}$. In addition, RO data can be used as benchmark measurements to inter-calibrate other instruments. COSMIC data are useful to distinguish the differences among NOAA15, 16 and 18 AMSU data, as well as to calibrate the AMSU data and identify AMSU locationdependent bias. RO data are further capable of assessing the quality of radiosonde data (diurnal bias due to radiative effects) as well as identifying diurnal effects on microwave satellite measurements.
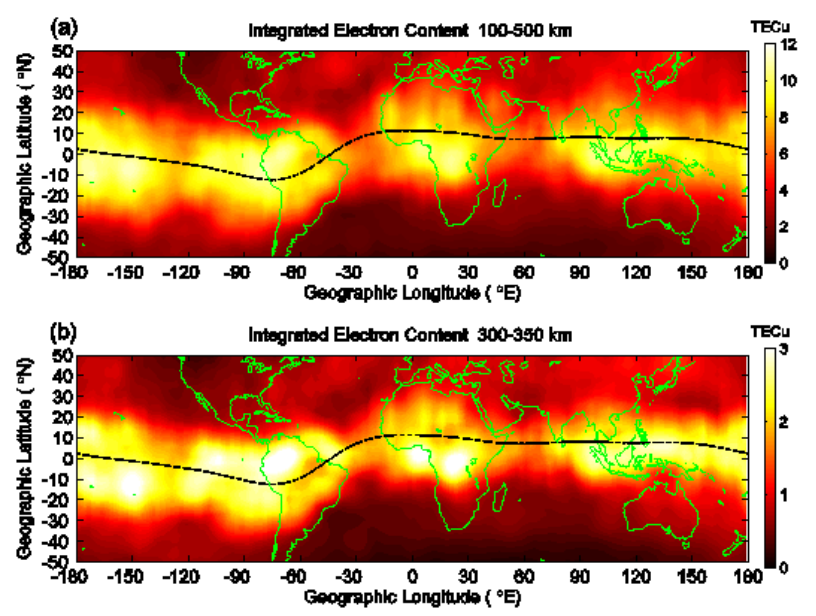

Fig. 39. 30-day mean vertically integrated electron content (TECu) for 20:00 to 22:00 local time over the layers $100-500 \mathrm{~km}$ (top) and $300-350 \mathrm{~km}$ (bottom) as observed by COSMIC during September 2006. TECu in $10^{12}$ electrons $\mathrm{cm}^{-2}$. Monthly averaged values obtained by binning measurements from 30 geomagnetically quiescent days ( 15 days prior and 15 days after 21 September) in two hour bins and taking median value of the soundings located in the same 5 degree by 5 degree grid in both longitude and latitude (Lin et al., 2007c).
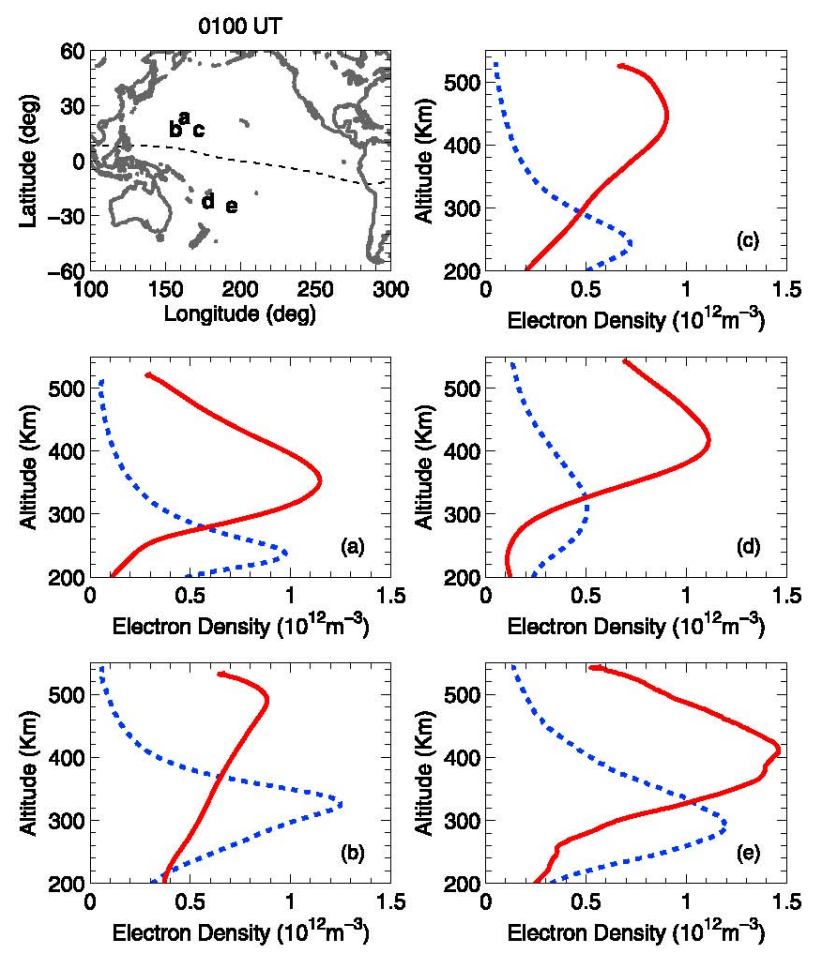

Fig. 40. Comparison of vertical electron density profiles from COSMIC on 14 December 2006 (before the geomagnetic storm, dashed blue) and 15 December 2006 (after the storm, solid red). The locations of the electron density profiles are indicated in the map at the top left (Pedatella et al., 2009). 
(a) COSMIC NmF2 : DAY 152-243, 2006 @ LT 11-14

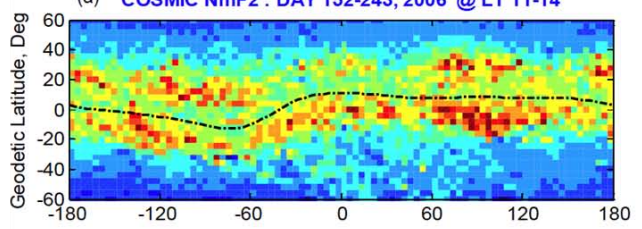

(b) IRI NmF2 : DAY 152-243, 2006 @ LT 11-14

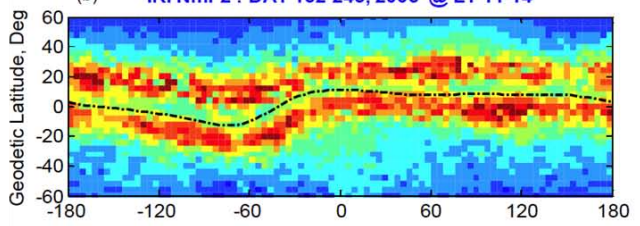

(c) TIEGCM NmF2: DAY $=170, F 107=80$, LT $=13$

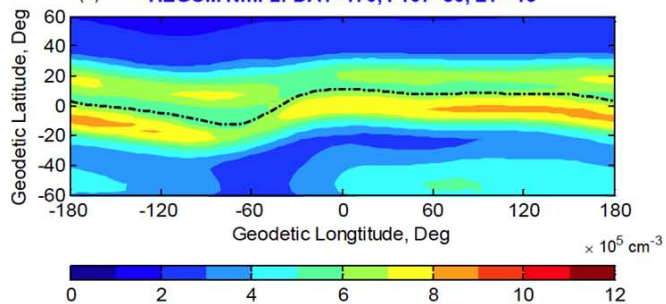

(a) COSMIC hmF2 : DAY 152-243, 2006 @T 11-14

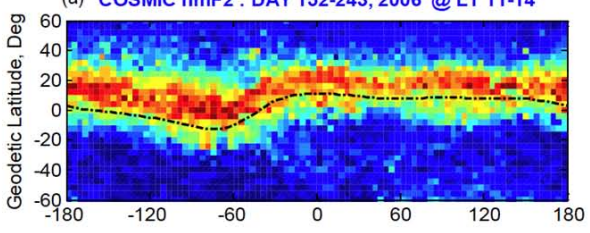

(b) IRI hmF2 : DAY 152-243, 2006 @ LT 11-14

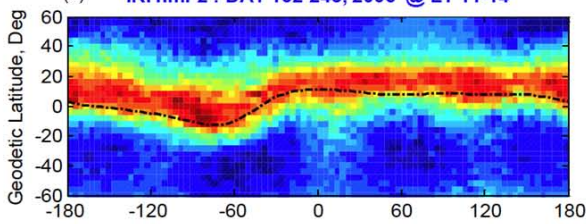

(c) TIEGCM hmF2: DAY $=170, F 107=80, L T=13$

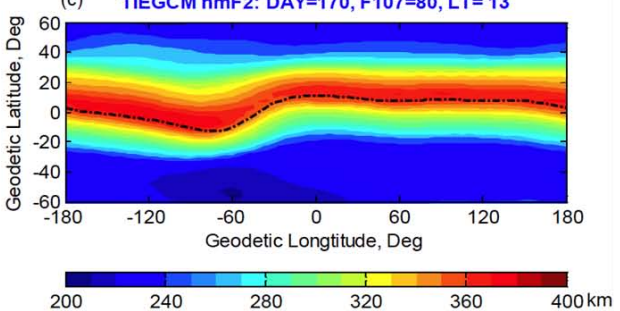

Fig. 41. Ionospheric climatology. Latitude-longitude plots of COSMIC measurements of the peak density and altitude in the equatorial ionization anomaly during the Northern Hemisphere summer (days 152-243) 2006 compared to: an empirical model (International 40. Reference Ionosphere) (IRI) and a numerical model (NCAR Thermosphere-Ionosphere-Electrodynamics General Circulation Model) (TIEGCM). Left panels: NmF2 from COSMIC (top), IRI (middle) and TIEGCM (bottom). Right side: hmF2 from COSMIC (top), IRI (middle) and TIEGCM (bottom) (Lei et al., 2007).
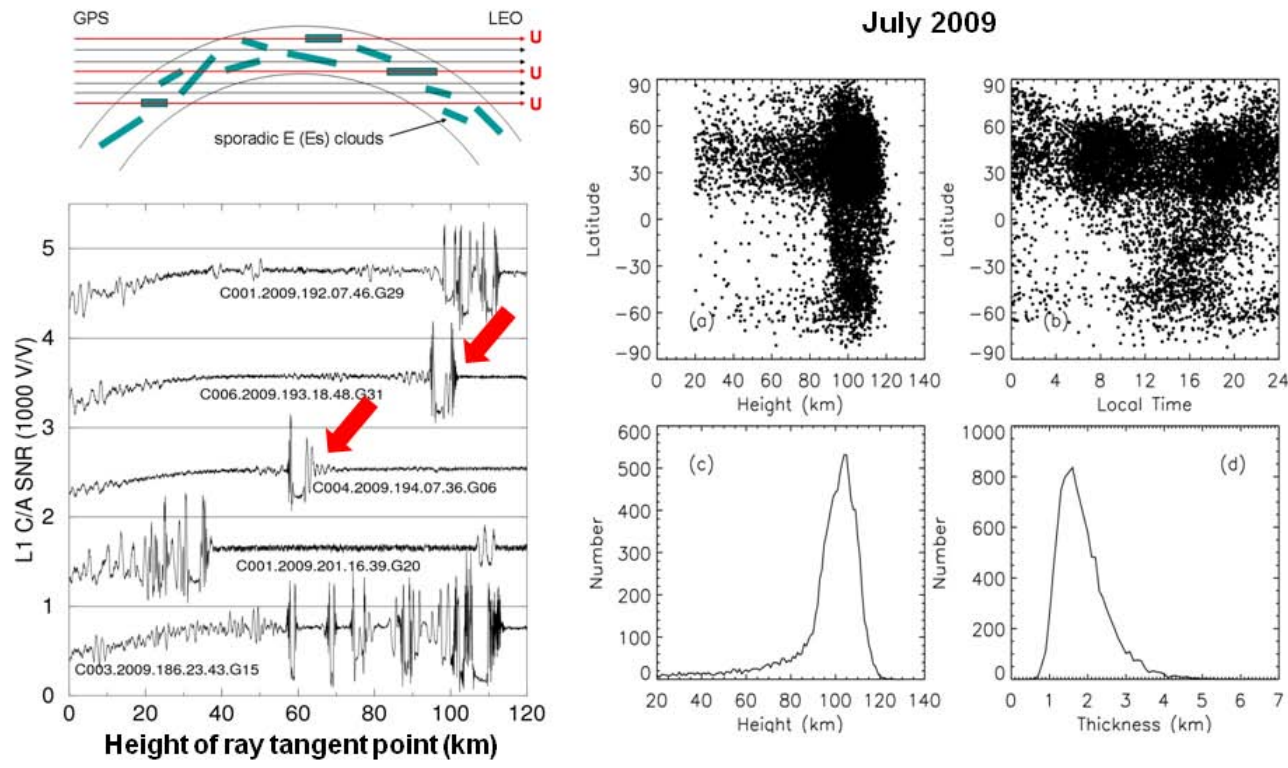

Fig. 42. Upper left: schematic diagram showing orientation of Es clouds that lead to U-shaped structures in the amplitude of RO signals. Upper right: location of Es clouds vs. latitude and local time. Lower left: amplitudes of COSMIC RO signals showing U-shaped structures (two prominent examples shown by red arrows). Lower right: number of Es clouds vs. thickness of Es clouds (Zeng and Sokolovskiy, 2010).

\section{Ionospheric research and space weather}

A major application of RO observations is in ionospheric research and space weather (Hajj et al., 2000). RO data are valuable for evaluation of ionospheric models and use in space weather data assimilation systems. Table 3 lists the space weather products available from COSMIC.

The retrieval of electron density profiles from RO observations is described by Leitinger et al. (1997), Schreiner et al. (1999), Syndergaard et al. (2006), and Lei et al. (2007). 


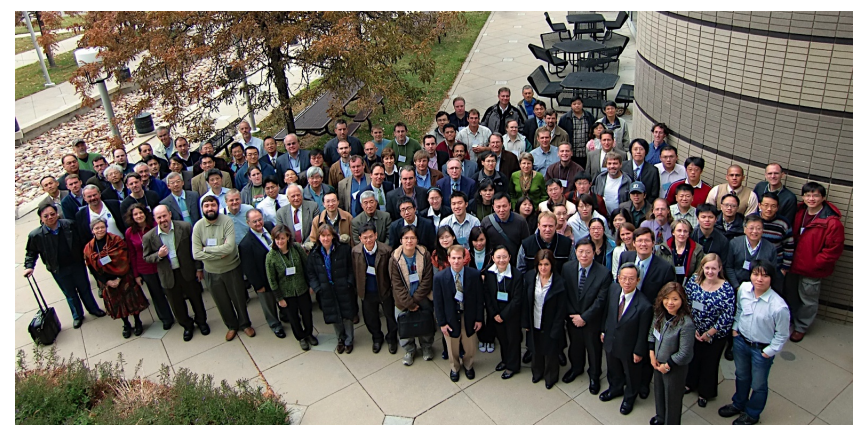

Fig. 43. Participants in fourth COSMIC Users' Workshop, October 2009, Boulder, Colorado (http://www.cosmic.ucar.edu/ oct2009workshop/index.html ) (Photo by Caryle Calvin, UCAR).

Lei et al. (2007) show some of the first comparisons made between COSMIC-derived electron density profiles and those measured by Incoherent Scatter Radars (ISR) at Millstone Hill and Jicamarca.

In many cases the COSMIC profiles agree well with the ISR measurements; however some retrievals using the standard Abel retrieval had significant errors as shown by the blue line in Fig. 37. These errors are caused by the assumption of local spherical symmetry in the Abel inversion and are discussed by Yue et al. (2010); they are greatest in low latitudes and low altitudes below the F layer. A recently developed method using a data assimilation technique (Yue et al., 2011) has shown significant improvements (dashed red line in Fig. 37). Figure 38 shows simulation results of the geomagnetic latitude and altitude variations of electron density during midday (local time $(\mathrm{LT})=13$ ) for the Abel and data assimilation retrievals; the assimilation method produces significantly smaller errors.

The large number of ionospheric observations provided by COSMIC has enabled the study of ionospheric phenomena at unprecedented horizontal and temporal resolution. Figure 39 shows the vertically integrated electron content in two layers, between 100 and $500 \mathrm{~km}$ and $300-350 \mathrm{~km}$ altitude (Lin et al., 2007c). A longitudinal wave number 4 structure is evident. The $1000-\mathrm{km}$ scale longitudinal variation in electron densities is not yet fully explained. Immel et al. (2006) suggest that the phenomenon is caused by ionospheric interactions with weather in the tropics. This kind of phenomenon, its diurnal and seasonal variation, and its height dependence can be studied in great detail with COSMIC data (Lin et al., 2007a,b, 2010).

Pedatella et al. (2009) used a combination of groundbased Global Positioning System (GPS) total electron content (TEC), TOPEX (ocean Topography Experiment) and Jason-1 TEC, and topside ionosphere/plasmasphere TEC, GPS radio occultation, and tiny ionospheric photometer (TIP) observations from COSMIC to study an ionospheric storm of long duration that occurred on 15 December 2006. This multi-instrument approach provided a unique view of the ionospheric positive storm effect by revealing the stormtime response in different altitude regions. The electron density profiles obtained by radio occultation demonstrated that the F layer peak height increased by more than $100 \mathrm{~km}$ during this time period (Fig. 40).

One use of COSMIC data has been the construction of ionospheric climatologies, such as those shown in Fig. 41. The latitude-longitude cross sections compare COSMIC measurements of the $\mathrm{F} 2$ layer peak electron density $(\mathrm{NmF} 2)$ and its height $(\mathrm{hmF} 2)$ near noon local time in the equatorial ionization anomaly to the International Reference Ionosphere (IRI) empirical model and a numerical model (NCAR Thermosphere-Ionosphere-Electrodynamics General Circulation Model, TIEGCM).

Arras et al. (2009) combined RO data from three RO missions - CHAMP, SAC-C, and COSMIC - to produce a twoyear climatology of the diurnal and semi-diurnal variations of the sporadic E layer (Es) for 2006 and 2007. The three RO missions provided an unprecedented $\sim 3000$ observations of electron density globally and showed a strong qualitative correlation of Es with the semi-diurnal tide (SDT) in zonal wind shear, a dominant feature of the midlatitude lower thermosphere.

This result supports the theory that zonal wind shear plays an essential role in Es formation at midlatitudes. Arras et al. (2009) concluded that "GPS RO observations have the potential to detect the seasonal mean SDT in Es and thus may provide a qualitative measure on lower thermosphere dynamics at altitudes above $100 \mathrm{~km}$ that are not accessible to most radar systems."

Zeng and Sokolovskiy (2010) have recently developed a new approach for studying the Es layer by RO. They found that Es clouds (regions of extremely dense ionization in the E layer at approximately $100 \mathrm{~km}$ altitude), when they are aligned with the propagation direction, result in specific "U-shaped" structures in RO amplitude that often lead to errors in the L2P (semi-codeless) PLL tracking. The U-shaped structures are observed in RO signals, but they were never understood and identified with Es clouds before. Es clouds can absorb, block or refract medium, high and very high frequency radio waves in an unpredictable manner. Figure 42 shows the latitude-height and latitude-time distribution of Es clouds (Zeng and Sokolovskiy, 2010).

The measurements of TEC and electron density profiles are potentially valuable for data assimilation into ionospheric models like the Jet Propulsion Laboratory/University of Southern California Global Assimilative Ionospheric Model (JPL/USC GAIM; Wang et al., 2004) and the Utah State University Global Assimilation of Ionospheric Measurements model (USU GAIM; Schunk et al., 2004, Scherliess et al., 2006). Many research groups running space weather models have assimilated TEC data. Komjathy et al. (2010) assimilated COSMIC measurements into GAIM and showed that the observations significantly improved the analysis of critical ionospheric parameters, such as $\mathrm{NmF} 2$ and $\mathrm{HmF} 2$ and 
vertical electron density profiles, as verified by comparisons to independent electron density profiles measured at Arecibo, Jicamarca, and Millstone Hill incoherent scatter radar (ISR). They also found that the COSMIC observations resulted in improvements in the global vertical TEC maps.

These results clearly show that the COSMIC data will be very useful for improving ionospheric data assimilation and forecast modeling and will make a significant contribution to space weather studies.

\section{Summary and some remaining challenges}

Since the launch of the proof-of-concept GPS/MET mission in 1995, it has become clear that RO has caused a revolution in atmospheric sounding. No other observing system provides such high-quality, global observations of the ionosphere, stratosphere and troposphere. These observations are having a high impact in operational weather forecasting, climate monitoring and research, as well as ionospheric research and space weather. The relatively low cost of RO observations compared to other space-based systems make them highly cost-effective for research and applications.

RO soundings, using open loop (OL) tracking in the troposphere, are significantly improved over RO soundings obtained from the Phase Locked Loop (PLL) technique. The negative refractivity bias in the lower troposphere present in earlier RO missions using PLL tracking is significantly reduced, and the fraction of soundings reaching to within one kilometer of Earth's surface is greatly increased. The OL technique also permits rising as well as setting occultations, and for the first time RO has shown a consistent ability to profile the vertical structure of the atmospheric boundary layer.

Studies using COSMIC data have verified the theoretical high precision of RO soundings; the precision of individual profiles in the upper troposphere/lower stratosphere is equivalent to about $0.05 \mathrm{~K}$ or higher. The accuracy and stability of RO observations has also been demonstrated, verifying that RO observations meet the high standards of climate benchmark observations.

RO observations have shown significant, positive impact on operational global weather forecasts and positive impacts on individual forecasts of important weather phenomena such as tropical cyclones. COSMIC data have been compared to data from AMSU on NOAA satellites (N15, N16 and N18). The COSMIC and AMSU brightness temperature data are highly correlated $(\sim 0.99$ or higher) with standard deviations to the mean between $0.95 \mathrm{~K}$ and $0.97 \mathrm{~K}$. The COSMIC data are capable of identifying inter-satellite offsets between the NOAA satellites, which demonstrate the value of $\mathrm{RO}$ observations in the inter-calibration of satellite data.

The COSMIC mission has generated many ionospheric, vertical profiles of electron density and total electron content. Ionospheric analyses of these observations have produced new insights into ionospheric structure and temporal variability, including Es clouds. The profiles are also useful in evaluating ionospheric models and space weather data assimilation systems.

Although the strengths and applications of RO observations have been amply demonstrated, a number of challenges and opportunities remain for increasing the value of this new observational tool. Among the most important challenges is to further clarify the quality of RO observations in the lower troposphere $(0-5 \mathrm{~km})$, where most of the atmospheric moisture resides. The biases present in the lowest few $\mathrm{km}$ of the atmosphere in early RO missions have been significantly reduced. There may remain a small bias in the lowest $2 \mathrm{~km}$ in regions of high water vapor in the tropics, although it is difficult to know for sure because of the absence of accurate, independent observations in this region.

Because of the uncertainties in the quality of lowertropospheric RO soundings, a conservative approach in assimilating lower-tropospheric RO observations in operational weather forecast models has been taken. It is this author's opinion that the maximum value of $\mathrm{RO}$ observations in this important region has not been achieved, and this provides a great opportunity for further advances. For example, advances in observation modeling in data assimilation systems could reduce the RO representativeness errors and lead to higher weights for the RO observations.

Another remaining challenge is associated with reduction of the errors in bending angles in the stratosphere and the error propagation downward via optimization and calculation of the refractivity by Abel inversion. In the classical optimization process, the retrieved bending angle is a combination of a first guess bending angle (e.g. from climatology) and the observed bending angle, with the weight of climatology being a maximum of one at the highest levels (e.g. $80 \mathrm{~km}$ ) and decreasing to zero at some lower altitude (e.g. $30 \mathrm{~km}$ ) where the observations are given full weight (Gobiet and Kirchengast, 2004; Kuo et al., 2004). Gobiet and Kirchengast (2004), Kuo et al. (2004), and Gobiet et al. (2007) show that the inversion errors associated with the observational noise, ad hoc optimization process and the choice of ancillary data (e.g. climatology) can be significant above $35 \mathrm{~km}$ in the stratosphere, especially at high latitudes over the polar region in winter. With the further inversion of refractivity using the Abel inversion, the influence of climatology can penetrate even below $35 \mathrm{~km}$. These errors can be reduced significantly by using only RO soundings with low noise (Kuo et al., 2004), but further work is needed to improve the accuracy of the retrieved bending angles and refractivities for operational NWP applications and climate studies.

Two other issues associated with COSMIC that limit its impact are the number of global soundings per day and the latency (time between the observation and when it is delivered to users). The 1500-2000 observations per day produced by the six COSMIC satellites are not enough to make a large impact in tropical cyclone prediction, since the average spacing of about $500 \mathrm{~km}$ in the tropics does not adequately 
resolve tropical storms and their environment. Furthermore, while the latency of a few hours is adequate for weather forecasting, a latency of 5-30 min is needed for real-time space weather forecasting. Both of these limitations can be addressed in future missions.

The future of RO looks bright, with a number of future missions carrying GPS receivers. A new constellation to replace COSMIC is now being planned by the US and Taiwan (Cook and Wilczynski, 2010) and will produce five to ten times as many RO soundings as COSMIC. Other constellations are being planned or considered, e.g. CICERO (Community Initiative for Continuing Earth Radio Occultation, http://geooptics.com/?page_id=58) and Iridium Next (http://www.uni-graz.at/opac2010/pdf_presentation/ opac_2010_gupta_omprakash_presentation79.pdf). Many satellite missions in the future will include RO receivers, e.g. the series of MetOp satellites that began with MetOp-A. In addition to these future LEO missions, other GNSS (Global Navigation Satellite Systems) constellations will provide signals that advanced $\mathrm{RO}$ receivers can use in addition to the $\sim 30$ GPS satellites. These include GLONASS, Galileo and Compass/Beidu. Each of these will consist of 24-30 transmitting satellites, representing significant increases in the number of possible RO soundings obtained by each LEO receiver. It is quite possible that by 2015 or so the number of RO soundings per day will exceed 10000 - five to ten times the number of RO soundings being produced today. These will have a major, positive impact on weather and space weather prediction; climate monitoring; and weather, climate and ionospheric research.

Acknowledgements. Many people, too numerous to mention, contributed over the past decade to the RO mission. The participants of the 2009 annual COSMIC users workshop, shown in Fig. 43, may be used as a symbol to represent all of these people. Also, many sponsors in the US, Taiwan and Europe have made the revolution possible. The work presented in this paper has been provided by many scientists around the world, and I thank them all for their contributions. Maura Hagan, Bill Kuo, Bill Schreiner and Sergey Sokolovskiy provided useful comments on this paper, and Susie Siders provided expert editorial assistance. Jens Wickert and Gottfried Kirchengast provided very helpful comments on the draft paper. My work is sponsored by the National Science Foundation, and I acknowledge Jay Fein, program manager for GPS/MET and COSMIC for his support over the years.

Edited by: U. Foelsche

\section{References}

Anthes, R. A., Rocken, C., and Kuo, Y.-H.: Applications of COSMIC to meteorology and climate, Terr. Atmos. Ocean. Sci., 11, 115-156, 2000.

Anthes, R. A., Kuo, Y.-H., Rocken, C., and Schreiner, W.: Atmospheric sounding using GPS radio occultation, MAUSAM, 54, 25-38, 2003.
Anthes, R. A., Bernhardt, P. A., Chen, Y., Cucurull, L., Dymond, K. F., Ector, D., Healy, S. B., Ho, S. P., Hunt, D. C., Kuo, Y.-H., Liu, H., Manning, K., McCormick, C., Meehan, T. K., Randel, W. J., Rocken, C., Schreiner, W. S., Sokolovskiy, S.V., Syndergaard, S., Thompson, D. C., Trenberth, K. E., Wee, T. K., Yen, N. L., and Zeng, Z.: The COSMIC/FORMOSAT-3 Mission-Early results, B. Am. Meteorol. Soc., 89, 313-333, 2008.

Ao, C. O., Meehan, T. K., Hajj, G. A., Mannucci, A. J., and Beyerle, G.: Lower troposphere refractivity bias in GPS occultation retrievals, J. Geophys. Res., 108(D18), 4577, doi:10.1029/2002JD003216, 2003.

Ao, C. O., Chan, T. K., Iijima, B. A., Li, J.-L., Mannucci, A. J., Teixeira, J., Tian, B., and Waliser, D. E.: Planetary boundary layer information from GPS radio occultation measurements, Proc. of the ECMWF GRAS SAF Workshop on Applications of GPS Radio Occultation Measurements, 16-18 June 2008, Reading, UK, 123-131 (paper available from: http://www.ecmwf.int/ publications/library/do/references/show?id=88751), 2008.

Ao, C. O., Hajj, G. A., Meehan, T. K., Dong, D., Iijima, B. A., Mannucci, A. J., and Kursinski, E. R.: Rising and setting GPS occultations by use of open loop tracking, J. Geophys. Res., 114, D04101, doi:10.1029/2008JD010483, 2009.

Arras, C., Jacobi, C., and Wickert, J.: Semidiurnal tidal signature in sporadic E occurrence rates derived from GPS radio occultation measurements at higher midlatitudes, Ann. Geophys., 27, 25552563, 2009,

http://www.ann-geophys.net/27/2555/2009/.

Beyerle, G., Wickert, J., Schmidt, T., and Reigber, C.: Atmospheric sounding by global navigation satellite system radio occultation: An analysis of the negative refractivity bias using CHAMP observations, J. Geophys. Res. 109, D01106, doi:10.1029/2003JD003922, 2004.

Beyerle, G., Schmidt, T., Wickert, J., Heise, S., Rotacher, M., König-Langlo, G., and Lauritsen, K. B.: Observations and simulations of receiver-induced refractivity biases in GPS radio occultation, J. Geophys. Res., 111, D12101, doi:10.1029/2005JD006673, 2006.

Beyerle, G., Grunwaldt, L., Heise, S., Köhler, W., König, R., Michalak, G., Rothacher, M., Schmidt, T., Wickert, J., Tapley, B. D., and Giesinger, B.: First results from the GPS atmosphere sounding experiment TOR aboard the TerraSAR$\mathrm{X}$ satellite, Atmos. Chem. Phys. Discuss., 10, 28821-28857, doi:10.5194/acpd-10-28821-2010, 2010.

Borsche, M., Kirchengast, G., and Foelsche, U.: Tropical tropopause climatology as observed with radio occultation measurements from CHAMP compared to ECMWF and NCEP analyses, Geophys. Res. Lett., 34, L03702, doi:10.1029/2006GL027918, 2007.

Cardinali, C.: Monitoring the observation impact on the short-range forecast, Q. J. Roy. Meteor. Soc., 135, 239-250, 2009a.

Cardinali, C.: Forecast sensitivity to observation (FSO) as a diagnostic tool, ECMWF Tech Memo., 599, 26 pp., Reading, UK, 2009 b.

Chen, S. Y., Huang, C.-Y., Kuo, Y.-H., Guo, Y.-R., and Sokolovskiy, S.: Assimilation of GPS refractivity from FORMOSAT3/COSMIC using a nonlocal operator with WRF 3DVAR and its impact on the prediction of a typhoon event, Terr. Atmos. Ocean. Sci., 20, 133-154, 2009.

Christy, J. R., Spencer, R. W., Norris, W. B., Braswell, W. D., and 
Parker, D. E.: Error estimates of Version 5.0 of MSU/AMSU bulk atmospheric temperatures, J. Atmos. Ocean. Tech., 20, 613629, 2003.

Cook, K. and Wilczynski, P.: COSMIC-2 weather forecasting and space weather monitoring in the 21 st century, Earthzine, 2010. http://www.earthzine.org/2010/10/13/cosmic-2-weatherforecasting-and-space-weather-monitoring-in-the-21st-century/

Cucurull, L.: Improvement in the use of an operational constellation of GPS Radio-Occultation receivers in weather forecasting, Weather Forecast., 25, 769-787, 2010.

Cucurull, L. and Derber, J. C.: Operational implementation of COSMIC observations into NCEP's Global Data Assimilation System, Weather Forecast., 23, 702-711, 2008.

Foelsche, U., Borsche, M., Steiner, A. K., Gobiet, A., Pirscher, B., Kirchengast, G., Wickert, J., and Schmidt, T.: Observing upper troposphere-lower stratosphere climate with radio occultation data from the CHAMP satellite, Clim. Dyn., 31, 49-65, doi:10.1007/s00382-007-0337-7, 2008a.

Foelsche, U., Kirchengast, G., Steiner, A. K., Kornblueh, L., Manzini, E., and Bengtsson, L.: An observing system simulation experiment for climate monitoring with GNSS radio occultation data: Setup and testbed study, J. Geophys. Res., 113, D11108, doi:10.1029/2007JD009231, 2008b.

Foelsch, U., Pirscher, B., Borsche, M., Kirchengast, G., and Wickert, J.: Assessing the climate monitoring utility of radio occultation data: From CHAMP to FORMOSAT3/COSMIC, Terr. Atmos. Oceanic Sci., 20(1), 155-170, doi:10.3319/TAO.2008.01.14.01(F3C), 2009.

Foelsche, U., Scherllin-Pirscher, B., Ladstädter, F., Steiner, A. K., and Kirchengast, G.: Refractivity and temperature climate records from multiple radio occultation satellites consistent within $0.05 \%$, Atmos. Meas. Tech. Discuss., 4, 1593-1615, doi:10.5194/amtd-4-1593-2011, 2011.

Foley, G. R.: Observations and analysis of tropical cyclones: WMO/TD 693-Global Perspectives on Tropical Cyclones, edited by: Elsberry, R., WMO, Geneva, 1-20, 1995.

Fomichev, V. I., Ward, W. E., Beagley, S. R., McLandress, C., McConnell, J. C., McFarlane, N. A., and Shepherd, T. G.: Extended Canadian Middle Atmosphere Model: Zonal-mean climatology and physical parameterizations, J. Geophys. Res., 107(D10), 4087, doi:10.1029/2001JD000479, 2002.

Gobiet, A. and Kirchengast, G.: Advancements of GNSS radio occultation retrieval in the upper stratosphere for optimal climate monitoring utility, J. Geophys. Res., 109, D24110, doi:10.1029/2004JD005117, 2004.

Gobiet, A., Kirchengast, G., Manney, G. L., Borsche, M., Retscher, C., and Stiller, G.: Retrieval of temperature profiles from CHAMP for climate monitoring: intercomparison with Envisat MIPAS and GOMOS and different atmospheric analyses, Atmos. Chem. Phys., 7, 3519-3536, doi:10.5194/acp-7-3519-2007, 2007.

Goody, R., Anderson, J., and North, G.: Testing climate models-An approach, B. Am. Meteorol. Soc., 79, 2541-2549, 1998.

Gorbunov, M. E.: Canonical transform method for processing radio occultation data in the lower troposphere, Radio Sci., 37, 1076, doi:10.1029/2000RS002592, 2002.

Gorbunov, M. E. and Gurvich, A. S.: Algorithms of inversion of Microlab-1 satellite data including effects of multipath propagation, Int. J. Remote Sen. 19, 2283-2300, 1998a.
Gorbunov, M. E. and Gurvich, A. S.: Microlab-1 experiment: Multipath effects in the lower troposphere, J. Geophys. Res. 103(D12) 13819-13826, 1998b.

Gorbunov, M. E. and Kornblueh, L.: Analysis and validation of GPS/MET radio occultation data, J. Geophys. Res. 196(D15), 17161-17169, 2001.

Gorbunov, M. E. and Lauritsen, K. B.: Analysis of wave fields by Fourier integral operators and their application for radio occultations, Radio Sci., 39, RS4010, doi:10.1029/2003RS002971, 2004.

Gurvich, A. S. and Krasil'nikova, T. G.: Navigation satellites for radio sensing of the Earth's atmosphere, Sov. J. Remote Sensing, 6, 89-93, 1987 (in Russian); 6, 1124-1131, 1990 (in English).

Hagan, M. E. and Forbes, J. M.: Migrating and nonmigrating diurnal tides in the middle and upper atmosphere excited by tropospheric latent heat release, J. Geophys. Res., 107(D24), 4754, doi:10.1029/2001JD001236, 2002.

Hagan, M. E. and Forbes, J. M.: Migrating and nonmigrating semidiurnal tides in the upper atmosphere excited by tropospheric latent heat release, J. Geophys. Res., 108(A2), 1062, doi:10.1029/2002JA009466, 2003.

Hajj, G. A., Lee, L. C., Pi, X., Romans, L. J., Schreiner, W. S., Straus, P. R., and Wang, C.: COSMIC GPS ionospheric sensing and space weather, Terr. Atmos. Ocean. Sci., 11, 235-272, 2000.

Hajj, G. A., Kursinski, E. R., Romans, L. J., Bertiger, W. I., and Leroy, S. S.: A technical description of atmospheric sounding by GPS occultation, J. Atmos. Sol. Terr. Phys., 64, 451-469, 2002.

Hajj, G., Ao, C. O., Iijima, B. A., Kuang, D., Kursinski, E. R., Mannucci, A. J., Meehan, T. K., Romans, L. J., de la Torre Juarez, M., and Yunck, T. P.: CHAMP and SAC-C atmospheric occultation results and intercomparisons, J. Geophys. Res., 109, D06109, doi:10.1029/2003JD003909, 2004.

Hau, L.-N., Kuo, Y.-H., Liu, J.-Y. and Cheng, C.-Z. (Eds.): Special issue on FORMOSAT-3/COSMIC mission results, Terr. Atmos. Ocean. Sci., 20, 1-295, doi:10.3319/TAO.2008.09.03.01(F3C), 2009.

He, W., Ho, S., Chen, H., Zhou, X., Hunt, D., and Kuo, Y.: Assessment of radiosonde temperature measurements in the upper troposphere and lower stratosphere using COSMIC radio occultation data, Geophys. Res. Lett., 36, L17807, doi:10.1029/2009GL038712, 2009.

Healy, S. B.: Forecast impact experiment with a constellation of GPS radio occultation receivers, Atmos. Sci. Lett., 9, 111-118, 2008.

Healy, S. and Eyre, J.: Retrieving temperature, water vapour and surface pressure information from a refractive-index profile derived by radio occultation: A simulation study, Q. J. Roy. Meteor. Soc., 126, 1661-1683, 2000.

Healy, S. B., Jupp, A. M., and Marquardt, C.: Forecast impact experiment with GPS radio occultation measurements, Geophys. Res. Lett., 32, L03804, doi:10.1029/2004GL020806, 2005.

Healy, S. and Thépaut, J. N.: Assimilation experiments with CHAMP GPS radio occultation measurements, Q. J. Roy. Meteorol. Soc., 132, 605-623, doi:10.1256/qj.04.182, 2006.

Ho, S.-P., Kuo, Y.-H., Zeng, Z., and Peterson, T.: A comparison of lower stratosphere temperature from microwave measurements with CHAMP GPS RO data, Geophys. Res. Lett., 34, L15701, doi:10.1029/2007GL030202, 2007.

Ho, S.-P., Goldberg, M., Kuo, Y.-H., Zou, C.-Z., and Schreiner, 
W.: Calibration of temperature in the lower stratosphere from microwave measurements using COSMIC radio occultation data: Preliminary results, Terr. Atmos. Ocean. Sci., 20, 87-100, 2009a.

Ho, S.-P., He, W., and Kuo, Y.-H.: Construction of consistent temperature records in the lower stratosphere using Global Positioning System radio occultation data and microwave sounding measurements, edited by: Steiner, A. K., Pirscher, B., Foelsche, U., and Kirchengast, G., New Horizons in Occultation Research, Springer, Berlin, 207-217, 2009b.

Ho, S.-P., Kirchengast, G., Leroy, S., Wickert, J., Mannucci, A. J., Steiner, A., Hunt, D., Schreiner, W., Sokolovskiy, S., Ao, C., Borsche, M., von Engeln, A., Foelsche, U., Heise, S., Iijima, B., Kuo, Y.-H., Kursinski, E. R., Pirscher, B., Ringer, M, Rocken, C., and Schmidt, T.: Estimating the uncertainty of using GPS radio occultation data for climate monitoring: Intercomparison of CHAMP refractivity climate records 2002-2006 from different data centers, J. Geophys. Res., 114, D23107, doi:10.1029/2009JD011969, 2009c.

Ho, S.-P., Kuo, Y.-H., Schreiner, W., and Zhou, X.: Using SItraceable Global Positioning System radio occultation measurements for climate monitoring, in: State of the Climate in 2009, B. Am. Meteorol. Sci., 91, S36-S37, 2010a.

Ho, S.-P., Zhou, X., Kuo, Y.-H., and Hunt, D.: Climate Calibration Observatory in Orbit: Calibration and Validation of Measurements of AMSU and AIRS using Global Positioning System Radio Occultation Observations, Joint OPAC-4 and GRAS SAF Climate Workshop, Graz, Austria, Sep. 610, 2010 b.

Hocke, K., Inversion of GPS meteorology data, Ann. Geophysicae, 15, 443-450, 1997.

Immel, T. J., Sagawa, E., England, S. L., Henderson, S. B., Hagan, M. E., Mende, S. B., Frey, H. U., Swenson, C. M., and Paxton, L. J.: Control of equatorial ionospheric morphology by atmospheric tides, Geophys. Res. Lett., 33, L15108, doi:10.1029/2006GL026161, 2006.

Jensen, A. S., Lohmann, M. S., Benzon, H., and Nielsen, A. S.: Full spectrum inversion of radio occultation signals, Radio Sci., 38(3), 1040, doi:10.1029/2002RS002763, 2003.

Jensen, A. S., Lohmann, M. S., Nielsen, A. S., and Benzon, H.: Geometric optics phase matching of radio occultation signals, Radio. Sci., 39, RS3009, doi:10.1029/2003RS002899, 2004.

Kalnay, E., Kanamitsu, M., Kistler, R., Collins, W., Deaven, D., Gandin, L., Iredell, M., Saha, S., White, G., Woollen, J., Zhu, Y., Chelliah, M., Ebisuzaki, W., Higgins, W., Janowiak, J., Mo, K. C., Ropelewski, C., Wang, J., Leetmaa, A., Reynolds, R., Jenne, R., and Joseph, D.: The NCEP/NCAR 40-Year Reanalysis Project, B. Am. Meteorol. Soc., 77, 437-471, 1996.

Komjathy, A., Wilson, B., Pi, X., Akopian, V., Dumett, M., Iijima, B., Verkhoglyadova, O., and Mannucci, A. J.: JPL/USC GAIM: On the impact of using COSMIC and ground-based GPS measurements to estimate ionospheric parameters, J. Geophys. Res., 115, A02307, doi:10.1029/2009JA014420, 2010.

Kuo, Y.-H., Zou, X., Chen, S. J., Huang, W., Guo, Y.-R., Anthes, R. A., Exner, M., Hunt, D., Rocken, C., and Sokolovskiy, S.: A GPS/MET sounding through an upper-level front, B. Am. Meteorol. Soc., 79, 617-626, 1998.

Kuo, Y.-H., Wee, T.-K., Sokolovskiy, S., Rocken, C., Schreiner, W., Hunt, D., and Anthes, R. A.: Inversion and error estimation of GPS radio occultation data, J. Meteor. Soc. Japan, 82, 507-531, 2004.
Kuo, Y.-H., Schreiner, W. S., Wang, J., Rossiter, D. L., and Zhang, Y.: Comparison of GPS radio occultation soundings with radiosondes, Geophys. Res. Lett., 32, L05817, doi:10.1029/2004GL021443, 2005.

Kursinski, E. R., Hajj, G. A., Bertiger, W. I., Leroy, S. S., Meehan, T. K., Romans, L. J., Schofield, J. T., McCleese, D. J., Melbourne, W.G., Thornton, C. L., Yunck, T. P., Eyre, J. R., and Nagatani, R. N.: Initial results of radio occultation of Earth's atmosphere using the global positioning system, Science, 271, 1107-1110, 1996.

Kursinski, E. R., Hajj, G. A., Hardy, K. R., Schofield, J. T., and Linfield, R.: Observing Earth's atmosphere with radio occultation measurements, J. Geophys. Res., 102, 23429-23465, 1997.

Kursinski, E. R., Hajj, G. A., Leroy, S. S., and Herman, B.: The GPS radio occultation technique, Terr. Atmos. Ocean. Sci., 11, 53-114, 2000.

Lackner, B. C., Steiner, A. K., Hegerl, G. C., and Kirchengast, G.: Atmospheric climate change detection by radio occultation data using a fingerprinting method, J. Climate, doi:10.1175/2011JCLI3966.1, in press, 2011.

Ladstädter, F., Steiner, A. K., Foelsche, U., Haimberger, L., Tavolato, C., and Kirchengast, G.: An assessment of differences in lower stratospheric temperature records from (A)MSU, radiosondes, and GPS radio occultation, Atmos. Meas. Tech. Discuss., 4, 2127-2159, doi:10.5194/amtd-4-2127-2011, 2011.

Lee, L.-C., Rocken, C., and Kursinski, R. (Eds): Special issue for applications of the Constellation Observing System for Meteorology, Ionosphere and Climate (COSMIC), Terr. Atmos. Ocean. Sci., 11, 379 pp., 2000.

Lei, J., Syndergaard, S., Burns, A. G., Solomon, S. C., Wang, W., Zeng, Z., Roble, R. G., Wu, Q., Kuo, Y.-H., Holt, J. M., Zhang, S.-R., Hysell, D. L., Rodrigues, F. S., and Lin, C. H.: Comparison of COSMIC ionospheric measurements with ground-based observations and model predictions: Preliminary results, J. Geophys. Res., 112, A07308, doi:10.1029/2006JA012240, 2007.

Leitinger, R., Ladreiter, H.-P., and Kirchengast, G.: Ionosphere tomography with data from satellite reception of Global Navigation Satellite System signals and ground reception of Navy Navigation Satellite System signals, Radio Sci., 32, 1657-1669, 1997.

LeMarshall, J., Xiao, Y., Norman, R., Zhang, K., Rea, A., Cucurull, L., Seecamp, R., Steinie, P., Puri, K., and Le, T.: The beneficial impact of radio occultation observations on Australian regional forecasts. Aust. Meteorol. Ocean. J., 62, 121-125, 2010.

Leroy, S. S., Anderson, J. G., and Dykema, J. A.: Testing climate models using GPS radio occultation: A sensitivity analysis, J. Geophys. Res., 111, D17105, doi:10.1029/2005JD006145, 2006a.

Leroy, S. S., Dykema, J. A., and Anderson, J. G., Climate benchmarking using GNSS occultation, in: Atmosphere and Climate: Studies by Occultation Methods, edited by: Foelsche, U., Kirchengast, G., and Steiner, A., Springer-Verlag, Berlin Heidelberg, 287-301, 2006b.

Lin, C.-H., Liu, J. Y., Fang, T. W., Chang, P. Y., Tsai, H. F., Chen, C. H., and Hsiao C. C.: Motions of the equatorial ionization anomaly crests imaged by FORMOSAT-3/COSMIC, Geophys. Res. Lett., 34, L19101, doi:10.1029/2007GL030741, 2007 a.

Lin, C. H., Hsiao, C. C., Liu, J. Y., and Liu, C. H.: Longitudinal structure of the equatorial ionosphere: Time evolution of the four-peaked EIA structure, J. Geophys. Res., 112, A12305, 
doi:10.1029/2007JA012455, 2007b.

Lin, C. H., Wang, W., Hagan, M. E., Hsiao, C. C., Immel, T. J., Hsu, M. L., Liu, J. Y., Paxton, L. J., Fang, T. W., and Liu, C. H.: Plausible effect of atmospheric tides on the equatorial ionosphere observed by the FORMOSAT-3/COSMIC: Three-dimensional electron density structures, Geophys. Res. Lett., 34, L11112, doi:10.1029/2007GL029265, 2007c.

Lin, C. H., Liu, C. H., Liu, J. Y., Chen, C. H., Burns, A. G., and Wang, W.: Midlatitude summer nighttime anomaly of the ionospheric electron density observed by FORMOSAT-3/COSMIC, J. Geophys. Res., 115, A03308, doi:10.1029/2009JA014084, 2010.

Liu, H., Anderson, J., and Kuo, Y.-H.: Improved analysis and forecasts of Hurricane Ernesto's genesis (2006) using radio occultation data in an Ensemble Kalman Filter assimilation system, Mon. Weather Rev., submitted, 2011.

Luntama, J.-P., Kirchengast, G., Borsche, M., Foelsche, U., Steiner, A., Healy, S., von Engeln, A., O'Clerigh, E., and Marquardt, C.: Prospects of the EPS GRAS mission for operational atmospheric applications, B. Am. Meteorol. Soc., 89, 1863-1875, 2008.

Mannucci, A. J., Ao, C. O., Yunck, T. P., Young, L. E., Hajj, G. A., Iijima, B. A., Kuang, D., Meehan, T. K., and Leroy, S. S.: Generating climate benchmark atmospheric soundings using GPS occultation data, in: Atmospheric and Environmental Remote Sensing Data Processing and Utilization II: Perspective on Calibration/Validation Initiatives and Strategies, edited by: Huang, A. H. L. and Bloom, H. J., Proceedings of SPIE, 6301, ISBN: 9780819463807, 1 September, 2006.

Mears, C., Wang, J., Ho, S.-P., Zhang, L., and Zhou, X.: Total column water vapor, in: State of the Climate in 2009, B. Am. Meteorol. Sci., 91, S29-S31, 2010.

Melbourne, W. G., Davis, E., Duncan, C., Hajj, G, Hardy, K., Kursinski, E., Meehan, T., Young, L., and Yunck, T. P.: The application of spaceborne GPS to atmospheric limb sounding and global change monitoring, JPL Publ. 94-18, Pasadena, CA, 147 pp., 1994.

Neiman, P. J., Ralph, F. M., Wick, G. A., Kuo, Y.-H., Wee, T.-K., Ma, Z., Taylor, G. H., and Dettinger, M. D.: Diagnosis of an intense atmospheric river impacting the Pacific Northwest: Storm summary and offshore vertical structure observed with COSMIC satellite retrieval, Mon. Weather Rev., 136, 4398-4420, 2008.

Ohring G., Wielicki, B., Spencer, R., Emery, B., and Atlas, R.: Satellite instrument calibration for measuring global climate change - Report of a workshop, B. Am. Meteorol. Soc., 86, 1303-1313, 2005.

Pedatella, N. M., Lei, J., Larson, K. M., and Forbes, J. M.: Observations of the ionospheric response to the 15 December 2006 geomagnetic storm: Long-duration positive storm effect, J. Geophys. Res., 114, A12313, doi:10.1029/2009JA014568, 2009.

Pirscher, B., Foelsche, U., Borsche, M., Kirchengast, G., and Kuo, Y.-H.: Analysis of migrating diurnal tides detected in FORMOSAT-3/COSMIC temperature data, J. Geophys. Res., 115, D14108, doi:10.1029/2009JD013008, 2010.

Randel, W. J., Wu, F., and Rivera Rios, W.: Thermal variability of the tropical tropopause region derived from GPS/MET observations, J. Geophys. Res., 108, D14024, doi:10.1029/2002JD002595, 2003.

Randel, W. J. and Wu, F.: Kelvin wave variability near the equatorial tropopause observed in GPS radio occultation measurements,
J. Geophys. Res., 110, D03102, doi:10.1029/2004JD005006, 2005.

Randel, W. J. and Wu, F.: The polar summer tropopause inversion layer. J. Atmos. Sci., 67, 2572-2581, 2010.

Ratnam, M. V. and Basha, S. G.: A robust method to determine global distribution of atmospheric boundary layer top from COSMIC GPS RO measurements, Atmos. Sci. Lett., 11, 216-222, doi:10.1002/asl.277, 2010.

Ringer, M. A. and Healy, S. B.: Monitoring twenty-first century climate using GPS radio-occultation bending angles, Geophys. Res. Lett., 35, L05708, doi:10.1029/2007GL032462, 2008.

Rocken, C., Anthes, R., Exner, M., Hunt, D., Sokolovskiy, S., Ware, R., Gorbunov, M., Schreiner, W., Feng, D., Herman, B., Kuo, Y.-H., and Zou, X.: Analysis and validation of GPS/MET data in the neutral atmosphere, J. Geophys. Res., 102, 29849-29866, doi:10.1029/97JD02400, 1997.

Scherliess, L., Schunk, R. W., Sojka, J. J., Thompson, D. C., and Zhu, L.: Utah State University Global Assimilation of Ionospheric Measurements Gauss-Markov Kalman filter model of the ionosphere: Model description and validation, J. Geophys. Res., 111, A11315, doi:10.1029/2006JA011712, 2006.

Schmidt, T., Heise, S., Wickert, J., Beyerle, G., and Reigber, C.: GPS radio occultation with CHAMP and SAC-C: global monitoring of thermal tropopause parameters, Atmos. Chem. Phys., 5, 1473-1488, doi:10.5194/acp-5-1473-2005, 2005.

Schmidt, T., Wickert, J., Beyerle, G., and Heise, S.: Global tropopause height trends estimated from GPS radio occultation data, Geophys. Res. Lett., 35, L11806, doi:10.1029/2008GL034012, 2008.

Schmidt, T., Wickert, J., and Haser, A.: Variability of the upper troposphere and lower stratosphere observed with GPS radio occultation bending angles and temperatures, Adv. Space Res., 46, 150-161, doi:10.1016/j.asr.2010.01.021, 2010.

Schreiner, W. S., Sokolovskiy, S. V., Rocken, C., and Hunt, D. C.: Analysis and validation of GPS/MET radio occultation data in the ionosphere, Radio Sci., 34, 949-966, 1999.

Schreiner, W., Rocken, C., Sokolovskiy, S., Syndergaard, S., and Hunt, D.: Estimates of the precision of GPS radio occultations from the COSMIC/FORMOSAT-3 mission, Geophys. Res. Lett., 34, L04808, doi:10.1029/2006GL027557, 2007.

Schunk, R. W., Scherliess, L., Sojka, J. J., Thompson, D. C., Anderson, D. N., Codresco, M., Minter, C. F., Fuller-Rowell, T. J., Heelis, R. A., Hairston, M., and Howe, B. M.: Global Assimilation of Ionospheric Measurements (GAIM), Radio Sci., 39, RS1S02, doi:10.1029/2002RS002794, 2004.

Sokolovskiy, S.: Tracking tropospheric radio occultation signals from low Earth orbit, Radio Sci., 36, 483-498, 2001.

Sokolovskiy, S.: Effect of super refraction on inversions of radio occultation signals in the lower troposphere, Radio Sci., 38, 1058, doi:10.1029/2002RS002728, 2003.

Sokolovskiy, S., Rocken, C., Hunt, D., Schreiner, W., Johnson, J., Masters, D., and Esterhuizen, S.: GPS profiling of the lower troposphere from space: Inversion and demodulation of the openloop radio occultation signals, Geophys. Res. Lett., 33, L14816, doi:10.1029/2006GL026112, 2006a.

Sokolovskiy, S., Kuo, Y.-H., Rocken, C., Schreiner, W. S., Hunt, D., and Anthes, R. A.: Monitoring the atmospheric boundary layer by GPS radio occultation signals recorded in the open-loop mode, Geophys. Res. Lett., 33, L12813, 
doi:10.1029/2006GL026112, 2006b.

Sokolovskiy, S. V., Rocken, C., Lenschow, D. H., Kuo, Y.-H., Anthes, R. A., Schreiner, W. S., and Hunt, D. C.: Observing the moist troposphere with radio occultation signals from COSMIC, Geophys. Res. Lett., 34, L18802, doi:10.1029/2007GL030458, 2007.

Sokolovskiy, S., Lenschow, D., Rocken, C., Schreiner, W., Hunt, D., Kuo, Y.-H., and Anthes, R.: Variability of the boundary layer depth over certain regions of subtropical ocean from 3 years of COSMIC data, Presentation at the 90th AMS Annual Meeting, Atlanta, GA, USA, 17-21 January 2010.

Sokolovskiy, S., Rocken, C., Schreiner, W., Hunt, D., and Johnson, J.: Postprocessing of L1 GPS radio occultation signals recorded in open-loop mode, Radio Sci., 44, RS2002, doi:10.1029/2008RS003907, 2009.

Steiner, A. K., Kirchengast, G., and Ladreiter, H. P.: Inversion, error analysis, and validation of GPS/MET occultation data, Ann. Geophys., 17, 122-138, doi:10.1007/s00585-999-0122-5, 1999.

Steiner, A. K. and Kirchengast, G.: Gravity wave spectra from GPS/MET occultation observations, J. Atmos. Oceanic Technol., 17, 495-503, 2000.

Steiner, A. K., Kirchengast, G., Foelsche, U., Kornblueh, L., Manzini, E., and Bengtsson, L.: GNSS occultation sounding for climate monitoring, Phys. Chem. Earth (A), 26, 113-124, 2001.

Steiner, A. K., Kirchengast, G., Borsche, M., Foelsche, U., and Schoengassner, T.: A multi-year comparison of lower stratospheric temperatures from CHAMP radio occultation data with MSU/AMSU records, J. Geophys. Res., 112, D22110, doi:10.1029/2006JD008283, 2007.

Steiner, A. K., Kirchengast, G., Lackner, B. C., Pirscher, B., Borsche, M., and Foelsche, U.: Atmospheric temperature change detection with GPS radio occultation 1995 to 2008, Geophys. Res. Lett., 36, L18702, doi:10.1029/2009GL039777, 2009.

Stephens, S. A. and Thomas, J. B.: Controlled-root formulations for digital phase-locked loops, IEEE Trans. Aerospace Electron Syst., 31(1), 78-95, 1995.

Syndergaard, S., Schreiner, W. S., Rocken, C., Hunt, D. C., and Dymond, K. F.: Preparing for COSMIC: Inversion and analysis of ionospheric data products, in: Atmosphere and Climate: Studies by Occultation Methods, edited by: Foelsche, U., Kirchengast, G., and Steiner, A. K., Springer-Verlag, Berlin Heidelberg, 137146, 2006.

Tsuda, T., Nishida, M., Rocken, C., and Ware, R. H.: A global morphology of gravity wave activity in the stratosphere revealed by the GPS Occultation Data (GPS/MET), J. Geophys. Res., 105, 7257-7273, 2000.

von Engeln, A., Teixeira, J., Wickert, J., and Buehler, S. A.: Using CHAMP radio occultation data to determine the top altitude of the planetary boundary layer, Geophys. Res. Lett., 32, L06815, doi:10.1029/2004GL022168, 2005.
Wang, C., Hajj, G., Pi, X., Rosen, I. G., and Wilson, B.: Development of the Global Assimilative Ionospheric Model, Radio Sci. 39, RS1S06, doi:10.1029/2002RS002854, 2004.

Ware, R., Exner, M., Feng, D., Gorbunov, M., Hardy, K., Herman, B., Kuo, Y., Meehan, T., Melbourne, W., Rocken, C., Schreiner, W., Sokolovskiy, S., Solheim, F., Zou, X., Anthes, R., Businger, S., and Trenberth, K.: GPS sounding of the atmosphere from low Earth orbit: Preliminary results, B. Am. Meteorol. Soc., 77, 19-40, 1996.

Wickert, J., Reigber, C., Beyerle, G., König. R., Marquardt, C., Schmidt, T., Grunwaldt, L., Galas, R., Meehan, T. K., Melbourne, W. G., and Hocke, K.: Atmosphere sounding by GPS radio occultation: First results from CHAMP, Geophys. Res. Lett., 28, 3263-3266, 2001.

Wickert, J., Schmidt, T., Beyerle, G., König. R., Reigber, C., and Jakowski, N.: The radio occultation experiment aboard CHAMP: Operational data processing and validation of atmospheric parameters, J. Meteorol. Soc. Jpn., 82, 381-395, 2004.

Wickert, J., Michalak, G., Schmidt, T., Beyerle, G., Cheng, C. Z., Healy, S. B., Heise, S., Huang, C. Y., Jakowski, N., Köhler, W., Mayer, C., Offiler, D., Ozawa, E., Pavelyev, A. G., Rothacher, M., Tapley, B., and Arras, C.: GPS radio occultation: Results from CHAMP, GRACE and FORMOSAT-3/COSMIC, Terr. Atmos. Ocean. Sci., 20(1), 3550, doi:10.3319/TAO.2007.12.26.01(F3C), 2009.

Xie, F., Wu, D. L., Ao, C. O., and Mannucci, A. J.: Atmospheric diurnal variations observed with GPS radio occultation soundings, Atmos. Chem. Phys., 10, 6889-6899, doi:10.5194/acp-10-68892010, 2010.

Yue, X., Schreiner, W. S., Lei, J., Sokolovskiy, S. V., Rocken, C., Hunt, D. C., and Kuo, Y.-H.: Error analysis of Abel retrieved electron density profiles from radio occultation measurements, Ann. Geophys., 28, 217-222, 2010, http://www.ann-geophys.net/28/217/2010/.

Yue, X., Schreiner, W. S., Lin, Y.-C., Rocken, C., Kuo, Y.-H., and Zhao, B.: Data assimilation retrieval of electron density profiles from radio occultation measurements, J. Geophys. Res., 116, A03317, doi:10.1029/2010JA015980, 2011.

Yunck, T. P, Liu, C.-H., and Ware, R.: A history of GPS sounding, Terr. Atmos. Ocean. Sci., 11, 1-20, 2000.

Zeng, Z., Randel, W., Sokolovskiy, S., Deser, C., Kuo, Y.-H., Hagan, M., Du, J., and Ward, W.: Detection of migrating diurnal tide in the tropical middle atmosphere using the Challenging Minisatellite Payload radio occultation data, J. Geophys. Res., 113, D03102, doi:10.1029/2007JD008725, 2008.

Zeng, Z. and Sokolovskiy, S.: Effect of sporadic E clouds on GPS radio occultation signals. Geophys. Res. Lett., 37, L18817, doi:10.1029/2010GL044561, 2010. 